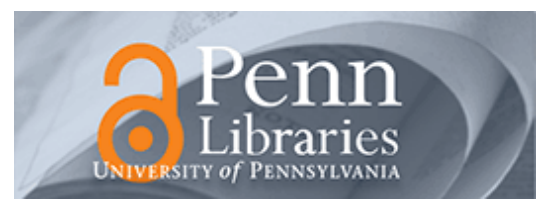

University of Pennsylvania

ScholarlyCommons

Management Papers

Wharton Faculty Research

3-2013

\title{
Breaking Them In or Eliciting Their Best? Reframing Socialization Around Newcomers' Authentic Self-Expression
}

Daniel M. Cable

Francesca Gino

Bradley R. Staats

University of Pennsylvania

Follow this and additional works at: https://repository.upenn.edu/mgmt_papers

Part of the Business Administration, Management, and Operations Commons, and the Human

Resources Management Commons

\section{Recommended Citation}

Cable, D. M., Gino, F., \& Staats, B. R. (2013). Breaking Them In or Eliciting Their Best? Reframing Socialization Around Newcomers' Authentic Self-Expression. Administrative Science Quarterly, 58 (1), 1-36. http://dx.doi.org/10.1177/0001839213477098

This paper is posted at ScholarlyCommons. https://repository.upenn.edu/mgmt_papers/82

For more information, please contact repository@pobox.upenn.edu. 


\title{
Breaking Them In or Eliciting Their Best? Reframing Socialization Around Newcomers' Authentic Self-Expression
}

\begin{abstract}
Socialization theory has focused on enculturating new employees such that they develop pride in their new organization and internalize its values. We draw on authenticity research to theorize that the initial stage of socialization leads to more effective employment relationships when it instead primarily encourages newcomers to express their personal identities. In a field experiment carried out in a large business process outsourcing company in India, we found that initial socialization focused on personal identity (emphasizing newcomers' authentic best selves) led to greater customer satisfaction and employee retention after six months than socialization that focused on organizational identity (emphasizing the pride to be gained from organizational affiliation) or the organization's traditional approach, which focused primarily on skills training. To confirm causation and explore the mechanisms underlying the effects, we replicated the results in a laboratory experiment in a U.S. university. We found that individuals working temporarily as part of a research team were more engaged and satisfied with their work, performed their tasks more effectively, and were less likely to quit when initial socialization focused on personal identity rather than on organizational identity or a control condition. In addition, authentic self-expression mediated these relationships. We call for a new direction in socialization theory that examines how both organizations and employees can benefit by emphasizing newcomers' authentic best selves.
\end{abstract}

\section{Keywords}

socialization, authenticity, self-expression, identity, best self, outsourcing, employee retention

\section{Disciplines}

Business Administration, Management, and Operations | Human Resources Management 
Running Head: SOCIALIZATION AND TURNOVER

\title{
Breaking Them in or Revealing Their Best? \\ Reframing Socialization Around Newcomer Self-expression
}

\author{
Daniel M. Cable \\ London Business School \\ Francesca Gino \\ Harvard University \\ Brad Staats \\ University of North Carolina at Chapel Hill \\ Forthcoming, Administrative Science Quarterly
}

\section{Acknowledgements}

We thank Drew Carton, Kathleen McGinn, and Jeff Polzer for their insightful comments on earlier drafts. We also thank Associate Editor Katherine Klein and three anonymous reviewers for their developmental and insightful comments throughout the review process. We are grateful to Devender Malhotra, Amit Rastogi, Rajesh Sehgal, Deepak Gupta, and others at Wipro BPO for their substantial investment of time and attention in this study, without which the work would not have been possible. Any remaining errors are our own. 


\begin{abstract}
Socialization theory has focused on enculturating new employees such that they develop pride in their new organization and internalize its values. Drawing on authenticity research, we propose that the initial stage of socialization leads to more effective employment relationships when it instead primarily encourages newcomers to express their personal identities. In a field experiment carried out in a large business process outsourcing company, we found that initial socialization focused on personal identity (emphasizing newcomers' authentic best selves) led to greater customer satisfaction and employee retention after six months as compared to (a) socialization that focused on organizational identity (emphasizing the pride to be gained from organizational affiliation) and (b) the organization's traditional approach, which focused primarily on skills training. To confirm causation and explore the mechanisms underlying the effects, we replicated the results in a laboratory experiment. We found that individuals working temporarily as part of a research team were more engaged and satisfied with their work, performed their tasks more effectively, and were more likely to return to work when initial socialization focused on personal identity as compared to a focus on organizational identity or a control condition. In addition, authentic self-expression mediated these relationships. We call for a new direction in socialization theory that examines how both organizations and employees benefit by emphasizing newcomers' authentic best selves.
\end{abstract}

\title{
Keywords
}

Socialization; Authenticity; Self-Expression; Identity; Best Self 
The desire to be authentic is a defining characteristic of the human experience. Defined as "the unobstructed operation of one's true, or core, self in one's daily enterprise" (Kernis, 2003: 13), authentic living allows individuals to achieve the most fulfilling and satisfying life possible, according to many philosophers, writers, and researchers (Guignon, 2004; Seligman, Steen, Park, and Peterson, 2005). Because organizations are made up of people, many of whom spend the majority of their waking hours at work, the human drive for authenticity creates a tension for organizations. On one hand, employers can address an essential yearning for authentic self-expression, helping employees articulate, project, and exercise their "best selves" at work (Roberts, Dutton, Spreitzer, Heaphy, and Quinn, 2005). On the other hand, organizations need to ensure continuity and control: they need their employees to behave in specified ways and express particular emotions in order to differentiate the organization's value production and succeed in the market (O'Reilly and Chatman, 1996; Pratt, 2000).

The potential for tension between employee self-expression and organizational control is perhaps most likely when new employees first enter an organization and encounter socialization. Organizational socialization is the process by which an individual acquires the values, expected behaviors, and social knowledge needed to assume an active role as a member of the organization (Louis, 1980; Van Maanen and Schein, 1979). When entering a new organization, newcomers usually experience anxiety as a result of being asked to question or put aside comfortable routines and assumptions, having their senses inundated with unfamiliar cues, and searching to fit in socially (Bauer, Morrison, and Callister, 1998; Feldman and Brett, 1983; Louis, 1980). For this reason, newcomers are particularly impressionable during their first few weeks in a new organization, and thus are vulnerable to organizational influence regarding appropriate behaviors, values, attitudes, and emotions (e.g., Schein, 1971; Van Maanen and Schein, 1979).

The initial stage of socialization, known as the encounter stage, is also a distinctive point in time during which employees must first negotiate their identities with peers and supervisors, and attempt to define acceptable roles for themselves within the new environment (Reichers 1987). During this stage, "a newcomer is likely to be concerned with building or confirming a situational identity," according to Reichers (1987: 280). Entering a new organization provides a rare fresh start for newcomers - a chance to show who they truly are and what they can do. Organizational entry is thus an unusual period in life when people can negotiate their identities 
anew; in most other aspects of life, we interact with people who have already implicitly agreed to honor the identities we have negotiated with them (Cable and Kay, 2012; Goffman, 1959; Ibarra, 2003). In addition to negotiating identity, newcomers may attempt to develop or innovate their new roles, thereby "imprinting the stamp of their identity and unique skills upon the role and its surrounding milieu" (Nicholson, 1984: 176).

Much of the socialization literature has focused on the ways that organizations can enculturate employees - that is, transmit and maintain the organization's culture by enabling them to understand and accept its identity and behavioral norms. As Bauer et al. (1998: 151) noted in their review of the literature: "When socialization is effective, newcomers understand and adopt the organization's central values and norms." From this vantage, the goal of many organizations is "absorption," or convincing newcomers to accept a new identity-namely, an organizational identity (Nicholson, 1984). This organizational identity can help newcomers fit in and understand and conform to organizational norms, thereby helping organizations overcome the difficulties associated with employees' idiosyncratic values, ideas, and perspectives (Sherif, 1958).

Although it clearly provides some benefits, the absorption model of enculturating newcomers falls short of resolving the tension newcomers may face when they are "processed" to accept an organization's identity and forego their own, at least while they are at work. First, newcomers may not internalize organizational values, even if they comply through external behaviors, which may prevent many desirable employee behaviors that are volitional and unscripted (O'Reilly and Chatman, 1986). Moreover, because suppressing one's identity is upsetting and psychologically depleting, subordinating a newcomer's individual identity and unique perspectives may not be optimal for either organizations or employees (Grandey, 2003; Hochschild, 1979, 1983; Kahn, 1990; Thoits, 1991). Thus, socialization practices that succeed in causing newcomers to behave inauthentically might not be sustainable because they do not address broader issues concerning emotional exhaustion and life dissatisfaction (Melamed, Shirom, Toker, Berliner, and Shapira, 2006; Seligman, 2002; Seligman et al., 2005). This issue may be particularly problematic in service roles, where employees are "on stage" as the face of the organization and are expected by customers to display certain cues and behaviors (Goffman, 1959; Grandey, 2003; Hochschild, 1979).

In this paper, we propose an alternative view of organizational socialization that 
addresses the basic needs of both organizations and newcomers. Drawing on authenticity research, we suggest that organizational socialization is optimized when organizations start by recognizing and highlighting newcomers' best selves at the very beginning of the employment relationship, when identity negotiation is a critical concern for both parties. Following Roberts et al. (2005: 713), we define a person's best self as the "individual's cognitive representation of the qualities and characteristics the individual displays when at his or her best." An individual's best self emerges from using and being recognized for his or her signature strengths, which increases his or her feelings of authenticity (Seligman et al., 2005).

We propose that, given an appropriate start, newcomers can frame their new role and its necessary tasks as opportunities to use their signature strengths and unique perspectives at work, thereby bringing more of their authentic best selves to the job. Thus, without disputing the organizational need for control or the employee benefits of reduced uncertainty, we suggest that the existing socialization literature can be strengthened by incorporating individuals' desire for authentic self-expression. Organizations that successfully channel this desire should realize greater commitment and higher quality work.

We conduct two studies to test this possibility. In our first study, we use a field experiment to examine whether initial socialization practices that promote individual identity versus organizational identity result in greater productivity and lower turnover. In our second study, we use a laboratory experiment to test whether individuals joining a new work environment are better enabled to authentically express their strengths when socialization practices emphasize their personal identities rather than the organizational identity, with consequences for engagement, productivity, job satisfaction, and turnover. By combining field and laboratory data, we help ensure both external and internal validity when testing our hypotheses.

In summary, this paper reveals a potential irony of modern organizational life. Although many leaders have focused on instilling organizational pride and culture to help newcomers internalize the organization's values, we propose that firms may discover even greater employee engagement, performance, and retention when they concentrate instead on newcomers' own identities from the start. As such, our research contributes to both the socialization and authenticity literatures. First, we propose that socialization research can gain traction by focusing on newcomers' authentic best selves, such that employers highlight newcomers' unique strengths 
and values and encourage them to align their external expressions with their internal states (Avolio and Gardner, 2005; Kahn, 1992; Roberts, 2012). From this perspective, rather than an idiosyncrasy to be resolved, newcomer identity is a resource to be leveraged during socialization, with counterintuitive positive effects on organizational commitment and productivity. Second, despite the fact that past research has framed authenticity striving as a personality trait (e.g., Cable and Kay, 2012; Wood et al., 2008), we find that regardless of employees' personality traits, organizational policies can strategically encourage authenticity at work with benefits to both parties.

\section{SOCIALIZATION TACTICS AND EMPLOYMENT RELATIONSHIPS}

The purpose of this article is to examine whether, during the initial stage of socialization, tactics that focus on newcomers' personal identities rather than organizational identity create stronger employment relationships and better employee performance. To that end, we first review the existing socialization literature, examining how strategic socialization has come to mean inculcating newcomers with organizational values, norms, and attitudes. Then we theorize about why employers may benefit when socialization practices encourage newcomers to display and engage their authentic best selves on the job.

The full process of socialization is an ongoing one that lasts for at least six months (e.g., Bauer et al., 1998) as newcomers learn the organization's values and how to fit into their new roles. Here, we focus on the initial stage of socialization - the time when newcomers first encounter organizational life. As discussed earlier, the tension between organizational enculturation and individual self-expression is greatest during this stage, thus suggesting that organizational processes should be particularly influential during this time.

\section{Socialization Theory}

There appear to be two dominant assumptions in the socialization literature (e.g., Bauer et al., 1998; Louis, 1980; Nicholson, 1984; Reichers, 1987; Van Maanen and Schein, 1979). First, transitions into organizations induce anxiety, which increases newcomers' susceptibility to influence. Second, organizations can strategically invest in structured tactics that produce relatively uniform responses across newcomers. "Like a sculptor's mold, certain forms of socialization can produce remarkably similar outcomes no matter what individual ingredients are used to fill the mold," note Van Maanen and Schein (1979: 231).

Conceptually, the defining characteristic of an organization's collection of socialization 
tactics is the extent to which they are designed to reduce the ambiguity about how one should behave that new employees face when joining the organization. In terms of how leaders can transition newcomers into their new roles, Van Maanen and Schein (1979) proposed a seminal framework of six different "people-processing" tactics. Subsequent validation of this framework has placed the six tactics on a single continuum ranging from individualized to institutionalized (e.g., Ashforth and Saks, 1996; Bauer et al., 1998; Cable and Parsons, 2001; Jones, 1986; Kim, Cable, and Kim, 2005; Lueke and Svyantek, 2000).

The goal of highly institutionalized socialization tactics is to remove uncertainty by conveying a consistent message to newcomers about the organization's values and how they should interpret and respond to situations. Nicholson (1984: 180) writes that "formal socialization will favor personal development" such that the newcomer alters his or her frame of reference, values, or other identity-related attributes to match those of the organization. Institutionalized socialization is exemplified by military basic training and by Disney's "Traditions 101," in which newcomers go through a structured, off-the-job training program with other newcomers. Conversely, individualized socialization tactics exacerbate uncertainty and encourage newcomers to challenge the status quo and rely on themselves to develop their own responses to the situations in which they find themselves on the job. Individualized socialization tactics force newcomers to "sink or swim" using their existing values and expose employees to different experiences. Given that newcomers feel anxiety and seek order at this early stage in the employment relationship, research shows that they are more likely to assume a "custodial" or "absorption" stance, accepting organizational values and norms as their own, when experiencing highly institutionalized socialization tactics as opposed to more individualized tactics (e.g., Cable and Parsons, 2001; Kim et al., 2005).

Thus, Van Maanen and Schein's (1979) original theory suggested that firms could either invest in institutionalized socialization tactics to inculcate their values and norms or invest in individualized tactics to encourage newcomers to question the status quo and bring their unique perspectives to the job. Conceptually, then, firms could strategically employ individualized tactics to leverage newcomers' uniqueness and increase their expression of their authentic best selves. In fact, Van Maanen and Schein (1979: 250) noted that rather than trying to divest newcomers of their identities, an individualized process "wishes to take advantage of and build upon the skills, values, and attitudes the recruit is thought to possess already." 
However, a careful examination of the socialization literature reveals that Van Maanen and Schein's (1979) proposed continuum - which they conceptualized as individualized-toinstitutionalized - actually has been reinterpreted in subsequent research as apathetic-toinstitutionalized socialization. That is, despite Van Maanen and Schein's (1979) brief discussion of the value of investing in individual-focused tactics that build upon newcomers' strengths, thanks to Jones' (1986) scale, the literature has defined non-institutional socialization as consisting of informal, low-investment tactics that reflect an absence of structure. As a result, firms investing in institutionalized socialization are advised to (a) put newcomers through a common set of off-the-job learning experiences while they learn their roles, (b) give newcomers explicit information about the sequence and timing of the stages they will go through in their new roles, and (c) provide experienced role models who offer social support for newcomers. Fulfilling this end of the socialization continuum obviously reflects substantial investment of time, energy, information, and money.

By contrast, the individualized end of the socialization continuum drops newcomers directly into their jobs without formal training, provides no information about the different stages of becoming an insider, and does not offer mentoring from experienced organizational members. This low investment, reactive approach to socialization could lead to innovation if newcomers' resulting confusion and uncertainty forced them to rely upon their own values and innovate new approaches to their tasks. Realistically, however, uncertainty may result in more discomfort than successful innovation; in fact, research suggests that people hold implicit biases against innovation, and these biases are activated when people feel motivated to reduce uncertainty (e.g., Mueller, Melwani, and Goncalo, 2012).

The proactivity stream of the socialization literature does advocate for a more active role for the individual in the socialization process. However, it also suggests that newcomers can and should take the initiative to learn and adopt the values of the organization (Ashford and Black, 1996; Bauer and Green, 1998; Bauer et al., 1998; Bell and Staw, 1989; Griffin, Colella, and Goparaju, 2000; Miller and Jablin, 1991; Morrison, 1993). Thus, rather than advising organizations to highlight and leverage newcomers' unique perspectives, proactivity research suggests that new employees can play an active role in networking and seeking information so that they can learn organizational norms and fit into the culture (e.g., Kim et al., 2005). In short, the proactivity research stream suggests that some newcomers are quite motivated to quickly 
"socialize themselves" into their new environment (Bauer et al., 1998).

What has not yet emerged in the socialization literature is an active, individualized approach to socialization that organizations can use strategically to encourage authentic expression of newcomers' identities. In this paper, we propose that organizations can formally structure personal-identity socialization, which we define as programs that help newcomers recognize and apply their authentic best selves to their new roles. Newcomer authenticity is an important new element in socialization research. Although Van Maanen and Schein's (1979) described investiture tactics that take advantage of newcomers' skills, values, and attitudes, they did not incorporate newcomers' desire for authentic self-expression as a key motivation during the socialization process, nor did they theorize about the possible synergistic positive effects for both newcomers and the organization if those needs were met. Moreover, Van Maanen and Schein's (1979) conceptual ideas became crystallized in all subsequent empirical research through Jones' (1986) scale, which (a) treated individualized socialization as no strategic socialization at all, and (b) reversed Van Maanen and Schein (1979) by placing the investiture tactic on the institutionalized end of the continuum.

Thus, the notion of using socialization strategically to facilitate newcomer authenticity does not appear in the past three decades of socialization research. Instead, the literature has focused on a continuum ranging from institutional socialization that is strategic and structured to individualized socialization that is apathetic, low-investment, and unstructured. Our research contributes by theorizing and demonstrating how structured investments in personal-identity socialization can in fact have a remarkable effect on the retention, job attitudes, work quality, and productivity of newcomers.

\section{Authenticity and Socialization}

With its emphasis on enculturating newcomers, it is easy to see how an institutional approach to socialization might lead to conflicts with authenticity. The core aspect of authenticity is that each person has a true inner self and can only achieve self-fulfillment as an authentic human being by expressing this inner self through actions in the external world (Guignon, 2004). Thus, to be authentic, we must align our internal experiences (e.g., feelings, values, perspectives) with our external expressions (Avolio and Gardner, 2005; Kahn, 1992; Roberts, 2012; Wood, Linley, Maltby, Baliousis, and Joseph, 2008).

Naturally, there may be elements of an individual's true self that are not part of his or her 
best self. Indeed, research has shown that people also are motivated to reveal negative aspects about themselves, even if this means making themselves look less than ideal (e.g., Cable \& Kay, 2011; Swann, Polzer, Seyle, and Ko, 2004). Although our true, authentic selves may have both positive and negative aspects, in this paper we focus on ways that organizations can elicit newcomers' authentic best selves. As such, we aim to reveal ways that the tenets of authenticity can be used to create conditions in which both individuals and organizations can thrive. Specifically, we argue that by encouraging newcomers to consider and express their authentic best selves, organizations can positively affect their job attitudes, performance, and retention. We base our prediction on three complementary streams of logic.

First, we know that people who alter or mute their unique values or perspectives in order to fit into an organization's dominant culture create a sense of alienation from themselves (Grandey, 2003: 89; Roberts, 2012) and must divert cognitive resources to cope with identity conflict (Bell, 1990; Hewlin, 2003; Higgins, 1989; Settles, Sellers and Damas, Jr., 2002). Perhaps not surprisingly, authenticity is associated with fewer depressive symptoms, lower emotional exhaustion, and less anxiety than a lack of authenticity (Goldberg and Grandey, 2007; Lopez and Rice, 2006; Ryan, LaGuardia and Rawsthorne, 2005; Zapf, 2002). Research also has shown that emotionally exhausted employees are more likely to quit and less likely to perform effectively and please customers than other employees are (Cropanzano, Rupp, and Byrne, 2003; Garman, Corrigan, and Morris, 2002; Maslach, Schaufeli, and Leiter, 2001; Taris, 2006; Wright and Cropanzano, 1998).

Second, people who feel they are acting authentically are more likely to attribute their behavior to internal causes than are those who feel they are acting inauthentically. This internalization increases commitment to a course of action (Kahn, 1990; Shamir, House, and Arthur, 1993) and promotes an optimal state of well-being characterized by feelings of enjoyment, personal meaning, and direction in life (Ilies, Morgeson and Nahrgang, 2005; Roberts, 2012; Ryff and Keyes, 1995; Waterman, 1993). Thus, we expect people to be more likely to invest energy in and less likely to leave environments where they have the opportunity to act authentically.

Finally, research suggests that people have a deep need to have others see them as they see themselves (Baumeister, 1998; Rogers, 1951; Swann, 1990) and that they withdraw from relationships where they feel they are not understood (for thorough reviews see Swann, 1990; 
Swann, Polzer, Seyle, and Ko, 2004). Research also has shown that people contribute better performance on creative tasks when members of their work group view them as they see themselves (Swann, Milton, and Polzer, 2000). Thus, when socialization practices encourage newcomers to display their authentic best selves, newcomers should be more satisfied with the employment relationship, less likely to quit, and more likely to perform well.

\section{Playing to Strengths}

Entering a new organization is stressful and threatening. One way to buffer newcomers against threat and encourage productive, authentic self-expression at work is to help them identify and leverage their best selves, or who they are when they are at their best (Roberts et al., 2005). Most people can recall times when they felt they were reaching their peak potential and that their contributions were being affirmed by others. For many people, using their signature strengths and being recognized for their best selves makes them feel more alive, truer to their

deepest selves, and as if they are pursuing their full potential as human beings. Not surprisingly, the state of being at one's best is often characterized by being authentic or true to oneself (Harter, 2002; Roberts, 2012).

The encounter phase of a socialization process represents a fresh start in a new social setting. "From an initial interaction with a recruiter to meeting one's new supervisor, newcomers have the opportunity to negotiate their identity through the way they act, the clothes they wear, and the way they describe themselves and their experiences," Cable and Kay (2012) write. Likewise, Ibarra (2003) argues that new social connections and new relationship development help people update their identities, since old connections bind people to old identities. In other words, the time of initial socialization offers an extraordinary opportunity for individuals to negotiate an identity with colleagues around their best self.

Thus, while socialization practices have traditionally concentrated on imbuing newcomers with organizational values, we propose that socialization practices could focus on soliciting and highlighting newcomers' best selves as they develop relationships in a new employment setting. Specifically, upon their entry, newcomers could be given time to reflect on personalized questions such as, "What three words best describe you as an individual?" and "What is unique about you that leads to your happiest times and best performance at work?" (Roberts et al., 2005). Likewise, newcomers could be encouraged to create a "personal highlights reel" by recalling times in their life when they felt they were using their signature strengths 
(Selk, 2008). If newcomers are given the opportunity to introduce themselves to new colleagues along the lines of their best selves, they can construct a positive social identity based on who they truly are (Roberts et al., 2005). Likewise, when they reflect on and formulate ways they can actively use their signature strengths in a new job, they can frame the job as an opportunity to be their best selves at work (Wrzesniewski and Dutton, 2001).

To summarize, several important outcomes should occur when socialization tactics encourage newcomers to reflect upon, highlight, and use their authentic best selves on the job. First, at this early pivotal point in relationship development, newcomers should react positively when an employer encourages them to introduce themselves along the lines of their authentic best selves. This encouragement should lead to greater feelings of connection with colleagues and more positive reactions to the employment relationship (Polzer, Milton, and Swann, 2002; Swann et al., 2004). And because newcomers who feel they are using their signature strengths at work should experience greater satisfaction, lower stress, and less emotional burnout, employee retention also should increase (Goldberg and Grandey, 2007; Ryan and Deci, 2001). In fact, the positive psychology literature has suggested that regularly using one's signature strengths improves life satisfaction and decreases depressive symptoms (Seligman et al., 2005). Finally, in terms of job performance, newcomers should invest more personal energy into their work when socialization practices frame the workplace as a place where they are understood for their authentic best selves and where they can reach goals by using their signature strengths (Roberts et al., 2005; Wrzesniewski and Dutton, 2001). Thus, we hypothesize:

Hypothesis 1. Socialization practices that emphasize newcomers' personal identities (i.e., their authentic best selves) will lead to greater organizational retention than socialization practices emphasizing organizational identity.

Hypothesis 2. Socialization practices that emphasize newcomers' personal identities (i.e., their authentic best selves) will lead to higher quality work than socialization practices emphasizing organizational identity.

Hypothesis 3. Socialization practices that emphasize newcomers' personal identities (i.e., their authentic best selves) will lead to greater engagement and more positive job attitudes than socialization practices emphasizing organizational identity.

Hypothesis 4. Newcomers' perceptions of authentic self-expression mediate the effect of socialization practices that emphasize newcomers' personal identities on (a) job attitudes, (b) 
productivity, and (c) retention.

\section{Overview of the Present Research}

Our hypotheses rely on psychological mechanisms: that is, when socialization practices emphasize personal identity rather than organizational identity, newcomers are more likely to express themselves for who they truly are, ultimately leading to better performance and higher retention. As such, it is important to both (a) test whether outcomes (i.e., job attitudes, turnover, and productivity) are differentially affected by different socialization practices and then (b) demonstrate why such effects occur (i.e., authentic self-expression).

To test our hypotheses, we conducted two studies. In Study 1, we tested Hypotheses 1 and 2 using a field experiment with new employees at a large business processing outsourcing firm. In Study 2, we conducted a laboratory experiment to constructively replicate our tests of Hypotheses 1 and 2, and to test Hypotheses 3 and 4.

\section{STUDY 1: METHOD}

\section{Sample and Procedures}

We conducted our first study, a field experiment, at Wipro BPO, an India-based, global leader in the business process outsourcing (BPO) industry. Wipro provides telephone and chat support for its global customers. The support provided varies by customer, but typically involves answering customer queries about Wipro's clients' services (e.g., buying an airline ticket) or products (e.g., configuring a printer).

An Indian call center provides an excellent context for studying the effects of socialization practices on employees' productivity and turnover, as such organizations routinely experience annual turnover rates ranging from 50-70\% (Budhwar, Verma, Malhotra, and Mukherjee, 2009). Like other companies in this industry, at the time of the field experiment, Wipro was experiencing high quit rates of call-center employees, with many employees burning out and quitting only a few months after completing their training. As a service role, the job can be stressful, not only because employees must help frustrated customers with their problems, but because Indian call center employees are often expected to "de-Indianize" many elements of their behavior - for example, by adopting a Western accent and attitude (Marantz, 2011).

Employees at Wipro, called agents, traditionally start their employment in batches of 15 to 25 people with whom they complete all of the training stages. Agents do not know which customer account (e.g., airline, printers) they will provide service to when they are hired. On the 
first day of arrival, Wipro holds an orientation during which new agents learn about Wipro and receive human resource information. Agents then complete two weeks of voice training in which they must exhibit competency in the English language (the language used with all customers that we studied).

Once language training is complete, agents are assigned to their customer account, where they receive approximately six weeks of process training. During process training, agents learn about their customers and the steps necessary to complete their work for customers. For instance, an agent providing technical service will be trained on the troubleshooting process to follow with inbound callers. Upon completion of process training, an agent moves to the floor, where she serves customers and undergoes on-the-job training. On-the-job training lasts approximately six weeks and consists of taking actual calls, with supervision, and additional classroom training to address issues identified on calls. Finally, agents transition to line operations, where they take calls full-time.

We implemented a field experiment around the initial socialization process in Wipro's telephone support operations. In this study, we assigned incoming batches of agents into three groups: (1) individual identity, (2) organizational identity, and (3) control group. ${ }^{1}$ Those in the two identity groups received the treatments described below. The control group went through Wipro's traditional socialization process, which focused primarily on skills training and general firm awareness. Specifically, newcomers were introduced to the responsibilities of their new role and then were assigned to the same customer accounts as the groups receiving a treatment in our investigation. Workers in the two identity groups received the same training and materials as the control group with the addition of the following three-part treatment: (1) a one-hour presentation during the first day's orientation session (described in detail below); (2) two fleece sweatshirts, customized by condition; and (3) one badge (the size of a typical agent-identity badge), customized by condition. With this one-hour treatment, we focused on initial newcomer socialization, in the sense that we influenced how newcomers were treated upon their arrival and earliest orientation to their new employer (i.e., the encounter stage). Of course, socialization is a process that unfolds across months, not hours (Bauer et al., 1998; Cable \& Parsons, 2001). Since

\footnotetext{
${ }^{1}$ We also included a group that received a team identity intervention. This group was divided into groups of five. For theoretical reasons, we decided to focus on the individual versus organizational-identity comparisons, but including these agents in the turnover models does not change our reported results. Moreover, we do not have equivalent customer satisfaction data for these employees, since there were no agents who received the team-identity treatment working for the customer for which we analyze customer satisfaction performance.
} 
socialization to norms and values clearly continued after our experimental conditions were completed, our results can be viewed as conservative effects that might be stronger with a longer-term intervention.

In the individual condition, the one-hour orientation session was run as follows. First, a senior leader from within Wipro spent 15 minutes discussing how working at Wipro would give each new agent the opportunity to express himself or herself and generate individual opportunities. ${ }^{2}$ Second, agents were given 15 minutes to individually complete a "lost at sea" exercise during which they ranked 15 items on their usefulness if the individual were to be stranded in a life raft at sea. This exercise is similar to other commonly used decision-making exercises, such as "arctic survival" and "desert survival." Our intent was to give newcomers an opportunity to do individual work that would permit self-reflection in the next part of the orientation session. Third, the agents were asked to spend 15 minutes thinking about how the decisions they had made in the exercise may have compared to other people's responses. Still working alone, newcomers wrote down answers to the following questions: (a) "What three words best describe you as an individual?" (b) "What is unique about you that leads to your happiest times and best performance at work?" (c) "Your Personal Highlights Reel: Reflect on a specific time - perhaps on a job, perhaps at home - when you were acting the way you were "born to act,"” and (d) "How can you repeat that behavior on this job?"

Finally, agents spent 15 minutes introducing their best selves to their future work group and discussing their answers and the approach they took to solving the exercise. At the end of this session, the agents were given two fleece sweatshirts with their individual names on them. They were also provided with a badge with their name on it. They were asked to wear the sweatshirts and badges during training.

The organizational condition also consisted of a one-hour session during agents' first day at the firm, where we mirrored the steps above but focused on organizational identity. First, a Wipro senior leader spent 15 minutes discussing Wipro's values and why it is an outstanding organization. Leaders were asked to discuss the organization's status and achievements during this talk. Second, a star performer at Wipro (e.g., an individual who had won the Employee of

\footnotetext{
${ }^{2}$ Senior leaders were not given a script to follow in any of the conditions, as the company felt that a script would be inconsistent with their socialization process. In this case, the leader was asked to give a 15-minute talk about how working at Wipro will give an individual the opportunity to be him/herself and create individual opportunities. The leader was asked to include examples from his or her own career at Wipro.
} 
the Quarter award) spoke for 15 minutes about Wipro's values and why it is an outstanding organization. Third, the agents were asked to spend 15 minutes alone writing answers to the following questions: (a) "What did you hear about the company that was most intriguing or appealing to you?" (b) "What did you hear about Wipro today that you would be proud to tell your family about?" and (c) "What did you hear about Wipro that makes you proud to be part of this organization?"

Finally, agents spent 15 minutes discussing their answers as a group. At the end of this session, the agents were given two fleece sweatshirts and a badge with the company name on it. As in the individual condition, agents were asked to wear the sweatshirts and badges during training.

\section{Empirical Strategy}

Our data includes information about each agent's demographic characteristics and time at Wipro. Our experimental manipulation targeted newcomers who joined Wipro from November 2010 until January 2011. We then collected an additional six months of data for all employees, including agents' operational performance. Due to the sensitivity of this data, we were able to collect it for only one of the customer accounts (described in more detail below). A total of 96 and 101 agents received the individual- and organizational-identity treatments, respectively. Our control group consisted of 408 agents (i.e., those not affected by the study) who received no identity treatment. The combined 605 agents were located in three different operations centers. Initially, three customer accounts were selected for the field experiment. However, two batches of agents who started in the organizational condition were assigned to a fourth customer when one of the initial three customers decided they did not need the additional agents. The reassigned agents were not aware that they had been reassigned, and dropping them from the analysis does not change the reported results. Tables $1 \mathrm{a}$ and $1 \mathrm{~b}$ provide a breakdown of agents by account and location.

$* * * * * * * * * * * * * * * * * * * * *$ Insert Tables $1 \mathrm{a}$ and $1 \mathrm{~b}$ about here

Our first hypothesis concerns whether agents in the different conditions departed the firm at different rates, based on their identity condition. We constructed a variable, turnover, equal to one if an agent left Wipro prior to May 30, 2011 (the end of data collection, approximately seven months after the experiments began) and equal to zero otherwise (later, to control for different number of days at the firm, we run a hazard analysis). Examining the differences in turnover 
rates across conditions, we find that the turnover rate in the control group was $47.2 \%$ higher than that of the individual-identity condition and $16.2 \%$ higher than that of the organizational-identity condition. Additionally, we find that turnover was $26.7 \%$ higher in the organizational-identity condition than in the individual-identity condition. To test our first hypothesis, we used the turnover variable in a conditional logistic regression. We conditioned on the customer account to control for time-invariant aspects of the customer being served (e.g., the difficulty of the process, characteristics of the individuals calling Wipro, etc.), and we also clustered our standard errors by the customer account. ${ }^{3}$ Therefore, for individual $i$, we estimate the following equation:

$$
\begin{gathered}
\text { Turnover }_{i}=\beta_{1} \text { Organizational }_{i}+\beta_{2} \text { Control }_{i}+\beta_{3} \text { Age }_{i}+\beta_{4} \text { Prior experience }_{i}+ \\
\beta_{5} \text { Male }_{i}+\beta_{6} \text { Location }_{i}+\varepsilon
\end{gathered}
$$

where Age and Prior experience are an agent's age when she joined Wipro and her months of prior experience at her start date, respectively. Additionally, we included an indicator variable for an agent's gender (Male) and location (Location). Customer account four and location three were co-linear with each other (i.e., only agents at customer account four were located at location three); therefore, we dropped the location three variable from the model. Finally, we entered the indicators for whether an agent was in the organizational condition (Organizational) or the control group (Control). Therefore, the individual condition is the missing condition, and the coefficients on both Organizational and Control should be interpreted relative to the individual condition.

Hypothesis 1 predicted that socialization practices emphasizing newcomers' personal identities (as occurred in the individual condition) lead to lower turnover than the firm's traditional socialization practices (control group) or socialization practices that emphasize the organization's identity (as occurred in the organizational condition). Thus, based on this hypothesis, we expected that $\beta_{1}>0$ and that $\beta_{2}>0$.

Second, to control for the fact that agents start at different times and may stay a different length of time, we estimated a Cox proportional hazards regression model. A hazard model permits us to examine how different covariates predict the time until an event occurs (in our case departure), while also accounting for censoring in the data (e.g., a worker not leaving the firm, Cleves, Gould and Guiterrez, 2004). We defined failure as an agent leaving the firm, and then

\footnotetext{
${ }^{3}$ An alternative empirical approach would be to control for differences across accounts by using a hierarchical linear model. We ran all turnover models using a mixed-effects logistic regression model where individuals are nested within accounts and replicate all reported results.
} 
estimate the hazard rate of an individual $i$ as:

$$
\begin{aligned}
& h\left(t \mid \mathbf{x}_{i}\right)= \\
& \mathrm{h}_{0}(t) * \exp \left(\gamma_{1} \text { Organizational }_{i}+\gamma_{2} \text { Control }_{i}+\gamma_{3} \text { Age }_{i}+\gamma_{4} \text { Prior experience }_{i}+\right. \\
& \left.\gamma_{5} \text { Male }_{i}+\gamma_{6} \text { Location }_{i}+\gamma_{7} \text { Account }_{i}\right)
\end{aligned}
$$

Time $t$ corresponds to days that the agent is present in the workforce at Wipro. We included the same control variables as in the conditional logistic regression model with standard errors clustered by customer account, although this time the account indicators were added directly to the model. In these models, the regression coefficients of interest are the indicators for the organizational-identity condition $-\gamma_{1}-$ and the control group $-\gamma_{2}$ (again, the missing category is the individual-identity condition). Based on Hypothesis 1, we expected that $\gamma_{1}>0$ and $\gamma_{2}>0$.

In addition to examining agents leaving the firm, we also examined the operational performance of those agents who stayed at the firm. In particular, Wipro provided customer satisfaction scores for agents in Account 2. Callers for Account 2 were randomly sampled after their calls were completed, and they were asked a number of questions about their experience, concluding with an overall question asking how satisfied they were with the agents' performance (the company only provided us with this overall measure). Performance scores vary from 0 to 100 percent with an average of 61 percent. We have information on an agent's average score from all of the customer satisfaction responses, and we use this value to generate the variable customer satisfaction. We used ordinary least squares regression to estimate the following model:

$$
\begin{aligned}
& \text { Customer satisfaction }_{i}= \\
& \qquad \begin{aligned}
& \delta_{1} \text { Organizational }_{i}+\delta_{2} \text { Control }_{i}+\delta_{3} \text { Age }_{i}+ \\
& \delta_{4} \text { Prior experience }_{i}+\delta_{5} \text { Male }_{i}+\delta_{6} \text { Location }_{i}+\varepsilon
\end{aligned}
\end{aligned}
$$

We again used the same control variables described above and the indicator variables for the organizational condition and the control group (the individual condition is the missing category). Hypothesis 2 predicted that when socialization practices emphasize newcomers' personal identities (i.e., individual condition), they result in higher-quality work than the firms' traditional socialization practices (control group) or the socialization practices that emphasize the organization's identity (organizational condition). Thus, based on this hypothesis, we expect $\delta_{\mathbf{1}}$ $<0$ and $\delta_{2}<0$. 
Table 2 provides an overview of the variables used in our analyses, while Table 3 provides summary statistics for the variables.

*********************Insert Tables 2 and 3 about here $* * * * * * * * * * * * * * * * * * * * * * * *$

\section{STUDY 1: RESULTS AND DISCUSSION}

Table 4 provides the conditional logistic regression results for models 1, 2, and 3 . Column 1 includes only the control variables; Column 2 adds the treatment indicators for the model on turnover. As predicted by Hypothesis 1, individuals in both the organizational-identity and control conditions were more likely to leave the firm as compared to those in the individualidentity condition. Specifically, the coefficients in Column 2 indicate that being in the organizational-identity $(\beta=1.252)$ or $\operatorname{control}(\beta=0.944)$ condition increases the odds of turnover by $250 \%$ and $157 \%$, respectively, as compared to the individual-identity condition. Moving to the hazard model in Columns 4 (control variables) and 5 (where the condition indicators are added), we again find support for Hypothesis $1 .^{4}$ The results reveal that the organizationalidentity $(\gamma=0.648)$ and control $(\gamma=0.769)$ conditions have a hazard ratio that is, on average, $91 \%$ and $116 \%$ higher than that of the individual-identity group, respectively. Although the organizational-identity condition had lower quit rates than the control condition, this difference was not statistically significant in Column 2 or Column 5.

****************************Insert Table 4 about here $* * * * * * * * * * * * * * * * * * * * * * * *$

Columns 7 and 8 provide the linear regression model on customer satisfaction performance. While both the organizational-identity and the control condition coefficients are negative, suggesting worse performance as compared to the individual-identity condition, only the comparison between the control group and the individual-identity condition was statistically significant. Thus, these results provide partial support for Hypothesis 2.

Finally, we examined the robustness of our results. We repeated the two turnover models on only accounts two and three, as these accounts have agents in the control group as well as in the individual-identity and organizational-identity conditions. As seen in Columns 3 and 6 of Table 4, the coefficients on the organizational-identity and control variables continued to be negative and statistically significant, providing further support for Hypothesis 1 . We could not repeat these tests for the model testing Hypothesis 2, as the operational data was only from one account. Additionally, we repeat models 1-3 using a linear probability model (OLS) and generate

\footnotetext{
${ }^{4}$ Duration data is missing for five individuals in the control group and so they are excluded from this analysis.
} 
the same pattern of results. Finally, we repeat the hazard models using a piecewise-constant hazard rate model and again generate the same pattern of results.

The results of our first study show that when the organization focused its initial socialization processes on newcomers' personal identities (i.e., authentic best selves) rather than on organizational identity, it fostered stronger employment relationships. Specifically, a focus on newcomers' unique perspective and strengths led to lower employee turnover than a focus on emphasizing pride from organizational affiliation, and also led to greater customer satisfaction as compared to the organization's traditional approach.

Although these results provided support for our first two hypotheses in an actual employment setting, they did not allow us to examine the proposed mediating mechanisms of self-expression. Furthermore, employees at an Indian call center may react differently to best-self socialization practices as compared to individuals from other cultures or other organizational contexts. To address these issues, we next conducted a controlled laboratory experiment. In this second study, we examine the effects of different socialization practices on both organizationally relevant outcomes (i.e., retention and productivity) and job attitudes (i.e., work engagement and satisfaction). In addition to examining the effects of personal-identity versus organizationalidentity socialization practices, this experiment also allowed us to examine whether perceived self-expression mediated the hypothesized relationships as compared to other plausible mechanisms. Finally, Study 2 included manipulation checks to confirm the effectiveness of our manipulations.

\section{STUDY 2: METHODS}

\section{Sample and Procedures}

One hundred seventy-five students from a university in the Northeastern United States (mean age $=22.47$, s.d. $=2.67,82$ male, 93 female) participated in the study for pay. We recruited participants for a three-hour study that would take place over two consecutive days. All participants completed the study on day 1 and were then given the choice of whether to come back on day 2 for the second part of the study. Participants received $\$ 35$ for their participation on day 1 (for a 120-minute session) and had the opportunity of earning an additional \$15 if they returned the second day (for another 60-minute session).

On day 1, after explaining that we were interested in understanding the factors that influence task performance, we told participants that they would be joining our research team 
during the study and would be working on a series of tasks, including a data-entry task from a recent experiment we had conducted and some problem-solving tasks. We manipulated only one factor between subjects: personal-identity socialization versus organizational-identity socialization versus a control condition. We conducted nine sessions and assigned three sessions to each of our three conditions.

In each session, participants first received the socialization manipulation and then engaged in a series of tasks for about 60 minutes. After the time had elapsed, we asked participants to answer a short survey, which included our measures of interest and manipulation checks. Participants were also invited to return to the laboratory the next day for another onehour session where they would be entering data. Participants could choose not to come back for the second day.

Identity manipulation. We introduced this manipulation at the beginning of each session of day 1 and modeled it after the manipulation used in the field experiment we conducted as Study 1 . However, in order to keep the experimenter blind to the study hypotheses and to the study conditions, we gave participants their instructions on the computer. In the individualidentity condition, students first spent about ten minutes reading about how working in the research lab would give each of them the opportunity to express themselves and generate individual opportunities (see the Appendix for our script). Second, students were asked to think about and write down answers to the following questions individually: (a) "What three words best describe you as an individual?" (b) "What is unique about you that leads to your happiest times and best performance at work or in school?" (c) "Your Personal Highlights Reel: Reflect on a specific time - perhaps on a job, perhaps at home - when you were acting the way you were 'born to act,"” and (d) "How can you repeat that behavior in this job today?" Students spent about 10-15 minutes working on these questions.

At the end of this procedure, participants were asked to use the materials at their desk (a piece of paper, colored pens, and markers) to write their own names creatively in a personalized logo so that they could be recognized as a member of the research team. They were asked to use their self-created nametag during the lab session by placing it next to the computer they would be using.

The organizational-identity condition consisted of a similar procedure. First, participants spent about ten minutes reading about the research lab's values and why it is an outstanding 
group (see the Appendix). Second, the participants spent time alone thinking about and writing down answers to three questions: (a) "What did you hear (if anything) about the research lab that was most intriguing or appealing to you?" (b) "What did you hear about the research lab today that you would be proud to tell your family about?" and (c) "What did you hear about the research lab that makes you proud to be part of it, even if for a short period of time?" Students spent about 10-15 minutes working on these questions.

At the end of this procedure, participants in this condition were asked to use the same materials to write the name of the research lab creatively on the piece of paper (i.e., to create a logo for the research team). As in the other condition, they were asked to place the logo next to their computers throughout the session.

In the control condition, participants received general information about the session and the research team they would be working for (see the Appendix). Next, they were asked to use the materials at their desk to create a creative logo for the research team and place it next to their computers throughout the session.

Participants in all three conditions spent the rest of the time working on a variety of tasks individually and spent the last ten minutes of the session on day 1 answering a short questionnaire with our measures of interest. As explained below, our survey measures included both job attitudes (i.e., engagement at work and job satisfaction) and two sets of manipulation checks. We also recorded data on organizationally relevant outcomes (i.e., performance on the data-entry task and turnover).

\section{Measures}

Unless otherwise indicated, all items used a Likert-type scale anchored at $1=$ "disagree strongly" and 7 = "agree strongly."

Dependent variable 1: Work engagement. To assess work engagement, we used four items from Schaufeli, Bakker, and Salanova's (2006) 17-item measure (i.e., "While working, I felt bursting with energy," "Time flew when I was working," "When I was working, I forgot everything else around me," and "I got carried away when I was working") $(\alpha=.91)$.

Dependent variable 2: Job satisfaction. We measured job satisfaction by using four items developed by Quinn and Shepard (1974). Participants were told that the items concerned their beliefs about their job as part of the research team that day, and they were asked to indicate their agreement with each of the beliefs stated (i.e., "All in all, I am very satisfied with this job," 
"If a friend told me she/he was interested in working in a job like this one I would strongly recommend it," "In general, this job measures up to the sort of job I wanted when I took it," and "Knowing what I know now, if I had to decide all over again whether to take this job, I would") $(\alpha=.89)$.

Dependent variable 3: Job performance. We measure productivity by counting the number of entries from surveys that participants completed in a 30-minute time period. Each survey included multiple pages and was printed on paper. Participants entered the data into Excel spreadsheets. To capture quality of performance, we also checked the number of errors made in the entries each participant completed.

Dependent variable 4: Retention. We measure retention by recording whether each participant returned to the laboratory to work as part of the research team on day $2(1=$ if the participant returned, $0=$ otherwise).

Mediator: Authentic self-expression. To measure authentic self-expression, we used a six-item scale from Waterman's Eudaimonic Well-Being Questionnaire Scale (see Waterman, 1993, 2005). For example, participants indicated the extent to which they agreed with items such as "In this job, I can be who I really am," "In this job, I feel authentic," and "In this job, I don't feel I need to hide who I really am" $(\alpha=.91)$.

Manipulation checks. We proposed that a socialization process stressing individuals' identities rather than the organization's identity would focus on employees' unique strengths and would require less conformity from newcomers. To capture these two elements, we assessed personal distinctiveness and socialization intensity. To assess the former, we asked participants to indicate their agreement with three items measuring personal distinctiveness (from Sheldon and Bettencourt, 2002) (i.e., "In this job, I feel like I stand out," "In this job, I felt unique," and "Within this research team, I felt like a distinctive person") $(\alpha=.93)$. To assess the latter, we asked participants to indicate their agreement with four statements measuring the intensity of the socialization process: 1) "I felt this research team wanted to change the way I act and solve problems," 2) "While working, I felt I had to conform to the team's way of thinking and acting," 3) "I felt that the teams was invading my personal space in terms of how I behaved and acted," and 4) "The way the research team asks new members to fit in is more extreme than other groups or organizations I have been part of in the past" $(\alpha=.83)$.

Alternative mechanisms. Conceptually, our identity manipulation may impact not only 
participants' authentic self-expression but other attitudes that could improve performance and retention and thus represent alternative explanations of the results. Accordingly, in our second study we included additional measures to test for the role of potential alternative mechanisms, including self-esteem, self-verification, and attraction toward other team members. We measured self-esteem with six items from Heatherton and Polivy's (1991) state self-esteem scale (e.g., "I felt confident about my abilities," "I felt like I was not doing well;" $\alpha=.87$ ). We measured selfverification with five items from Wiesenfeld, Swann, Brockner, and Bartel (2007) (e.g., "In this job, other team members see me as I see myself," "Around here, team members have an accurate view of who I am;” $\alpha=.90)$. Finally, we assessed attraction with eight items (e.g., "I feel close to this research team and its members," "It is likely that this research team's members and I could become friends if we interacted a lot"; $\alpha=.81$ ) from the relatedness scale of the intrinsic motivation inventory (Sheldon and Deci, 1996). We used this scale because relatedness captures individuals' desire to feel connected to others (Ryan, 1993).

\section{STUDY 2: RESULTS AND DISCUSSION}

Table 5 reports the summary statistics of the main variables assessed in the study. Means and standard deviations by condition for our focal variables appear in Table 6.

$* * * * * * * * * * * * * * * * * * * * * * * * * *$ Insert Tables 5 and 6 about here $* * * * * * * * * * * * * * * * * * * * * * * *$

\section{Manipulation Checks}

We first examined whether participants' beliefs about socialization intrusiveness varied across conditions and found that this was in fact the case $(F(2,172)=5.95, p=.003)$. Participants rated the socialization process as more intrusive in the organizational-identity condition than in both the individual-identity condition $(p=.006)$ and the control condition $(p=$ $.002)$. In addition, participants' perceived personal distinctiveness varied by condition $(F(2,172)$ $=6.49, p=.002$ ). Specifically, participants in the individual-identity condition reported greater personal distinctiveness than did participants in both the organizational-identity condition $(p=$ $.003)$ and in the control condition $(p=.002)$. Together, these results indicate that our manipulation was effective.

\section{Performance Effects}

As shown in Table 6, as compared to participants in both the organizational-identity condition and the control condition, those in the individual-identity (i.e., best self) condition reported being more engaged $(F(2,172)=3.50, p=.032)$ and more satisfied with their jobs $(F$ 
$(2,172)=4.59, p=.011)$, and they were also more likely to return to the laboratory a day later to do more work as part of the research team $\left(\chi^{2}(2, \mathrm{~N}=175)=6.18, p=.046\right)$. Participants in the individual-identity condition also performed more efficiently on the data-entry task than did participants in both the organizational-identity condition and the control condition $(F(2,172)=$ $9.25, p<.001)$. Importantly, they also committed fewer errors $(F(2,172)=5.23, p=.006)$, indicating that their work was of greater quality. We then considered only the correct entries participants completed and found that participants in the individual-identity condition performed better $($ mean correct entries $=105.57$, s.d. $=9.80)$ than those in both the organizational-identity condition (mean correct entries $=97.29$, s.d. $=11.12$ ) and the control condition (mean correct entries $=98.64$, s.d. $=5.91), F(2,172)=13.52, p<.001$. In all these analyses, post-hoc comparisons revealed that the differences on these measures between the individual-identity and the organizational-identity condition, as well as those between the individual-identity and the control condition, were all statistically significant at the $5 \%$ level.

\section{Authentic self-expression}

We predicted that participants would experience greater authentic self-expression in the individual-identity condition than in both the organizational-identity condition and the control condition. We found support for this prediction $(F(2,172)=3.47, p=.033)$. Results revealed that participants in the individual-identity condition reported higher levels of authentic selfexpression than did those in the organizational-identity condition $(p=.021)$ and the control condition $(p=.026)$.

\section{Additional Measures}

We conducted similar analyses to examine whether our identity manipulation impacted the additional measures we included in our second study, namely self-esteem, self-verification, and attraction. We found that it did not (all $p$-values $>.16$ ). As shown in the correlation reported in Table 5, however, all three measures were positively and significantly correlated with participants' self-reported authentic self-expression.

\section{Mediation Analyses}

Next, we tested whether authentic self-expression mediated the relationship between socialization (i.e., focused on personal identities versus focused on organizational identity or the control condition) and the various outcomes we measured: job attitudes (i.e., work engagement and job satisfaction), job performance, and retention. We conducted regression analyses that 
included an indicator for our individual-identity condition and an indicator for our organizational-identity condition. Given that we found no significant differences across the measures assessed in Study 2 between the organizational-identity and control conditions, when discussing our results below, we only comment on the coefficient that refers to the individualidentity condition.

When both socialization and authentic self-expression were entered into a regression model predicting work engagement, socialization was no longer significant $(B=.23, S E B=.23$; $t=1.00, p=.32$ ), whereas authentic self-expression significantly predicted work engagement $(B$ $=.57, S E B=.07 ; t=8.00, p<.001)$. The Preacher and Hayes (2004) bootstrapping technique (with 10,000 iterations) produced a 95\% bias-corrected confidence interval for the indirect effect that excluded zero (.03 to .64), thus suggesting a significant indirect effect.

When both socialization and authentic self-expression were entered into a regression predicting job satisfaction, socialization condition was no longer significant $(B=.39, S E B=.21$; $t=1.84, p=.07)$, whereas authentic self-expression significantly predicted job satisfaction $(B=$ $.51, S E B=.07 ; t=7.88, p<.001)$. The Preacher and Hayes (2004) bootstrapping technique (with 10,000 iterations) produced a 95\% bias-corrected confidence interval for the indirect effect that excluded zero (.02 to .61), thus suggesting a significant indirect effect.

Similarly, when both socialization and authentic self-expression were entered into a regression predicting job performance, socialization condition was reduced in significance (from $B=4.43, S E B=1.35 ; t=3.28, p=.001$ to $B=3.54, S E B=1.32 ; t=2.69, p=.008)$, and authentic self-expression significantly predicted job performance $(B=1.62, S E B=.40 ; t=4.03$, $p<.001)$. The $95 \%$ bias-corrected confidence interval for the indirect effect we obtained through the Preacher and Hayes (2004) bootstrapping technique (with 10,000 iterations) did not include zero (.12 to 2.22), thus suggesting a significant indirect effect. Importantly, we obtained the same results when considering only participants' correct entries. When both socialization and authentic self-expression were entered into a regression predicting the number of correct entries in the data-entry task, the effect of condition was significantly reduced $(B=6.25, S E B=1.72 ; t=3.64$, $p<.001)$, and authentic self-expression significantly predicted higher quality work $(B=1.24, S E$ $B=.52 ; t=2.37, p=.019 ; 95 \%$ bias-corrected $\mathrm{CI}=.05,1.96)$.

Finally, when both socialization and authentic self-expression were entered into a logistic regression model predicting retention, authentic self-expression was significant $(B=.69, S E B=$ 
.15 , Wald $\chi 2=22.40, p<.001)$, but socialization was no longer significant $(B=.66, S E B=.44$, Wald $\chi 2=2.28, p=.13$. Using the bootstrapping method (with 10,000 iterations) recommended by Preacher and Hayes (2004), we tested the significance of the indirect effect of socialization on retention through perceived authentic self-expression. The $95 \%$ bias-corrected confidence interval for the indirect effect did not include zero $(.03, .83)$, indicating that authentic selfexpression was a mediator, as we predicted.

Taken together, these results replicate the findings of Study 1 in a controlled, laboratory environment and also provide support for Hypotheses 3, 4a, 4b, and 4c. Notably, they also rule out the role of self-esteem, self-verification, and attraction to one's team members as potential alternative mechanisms of the effects of socialization processes that focus on personal identities on job attitudes, job performance, and retention.

\section{GENERAL DISCUSSION}

Organizations invest considerable resources to locate new employees whose personal values match the organization's culture (e.g., Chatman, 1991; Cable and Judge, 1997), but often it is not feasible to find a perfect match. Accordingly, many organizations use socialization processes as a second vehicle for transmitting and maintaining their cultures, such that new employees accept organizational values and behavioral norms (Bauer et al., 1998; Cable and Parsons, 2001; Chatman, 1991). Thus, the goal of many organizations' socialization practices is to help newcomers adopt a new organizational identity. In fact, many organizations require newcomers to wear standard wardrobes and follow detailed verbal scripts, forbid personal possessions, and enforce appropriate displays of emotion - all measures designed to suppress individuality (Martin, Knopoff, and Beckman, 1998; O’Reilly and Chatman, 1996).

Contrary to this traditional perspective on socialization, in both a field and a laboratory experiment we found that both organizational and employee outcomes were more positive when socialization tactics encouraged newcomers' authentic self-expression. In Study 1, the results suggested that a personal-identity approach, as compared to an organizational identity approach, led to significantly greater employee retention in an Indian call center after six months, producing customer satisfaction that was as high as the organizational-identity approach (and significantly higher than the organization's existing socialization procedures). We then replicated and extended these main findings in a laboratory experiment in which we examined job attitudes (i.e., work engagement and job satisfaction) in addition to job performance and retention, as in 
Study 1. Importantly, the results of our second experiment demonstrate that our hypothesized relationships are explained by greater levels of authentic self-expression.

Taken together, our studies provide evidence that authenticity at work can be promoted by emphasizing newcomers' authentic best selves. By integrating authenticity research with socialization theory, we developed novel, counterintuitive predictions about how framing socialization tactics around authenticity can have long-lasting effects on employees' psychological experience, their commitment to and satisfaction with their work, and critical organizational outcomes such as productivity, quality of work, and retention. The implications of this perspective for organizational commitment may be quite far reaching: that is, the best way for an organization to develop organizational commitment may be to commit to each of its members by highlighting and encouraging the daily use of their unique strengths.

\section{Theoretical Contributions}

Should newcomers be expected to forego their personal identities in order to fit in to a new role? Understanding how to effectively enculturate employees by "breaking them in" to an organizationally defined role (Van Maanen and Schein, 1979) has been the major focus of the socialization literature to date. This approach to organization-focused socialization clearly is useful to both organizations and newcomers in terms of removing ambiguity. Moreover, as compared to socialization focused on personal identity, organization-focused socialization also should trigger greater changes in newcomers' values, thereby helping them adapt to the organization's culture (Cable and Parsons, 2001).

By contrast, we propose that tactics emphasizing employees' personal identities ultimately may be more effective at strengthening employment relationships. We contend that while newcomers do seek to reduce uncertainty and fit in, they also yearn for authenticity. Namely, they want to feel that they can behave authentically in the environment where they spend the majority of their waking hours - to be recognized for who they are rather than being subsumed by an organizational identity. We argued and found that the concepts of newcomer authenticity and self-expression are integrated into socialization processes. Thus, firms can make strategic investments in individualized socialization tactics that facilitate expression of their best selves, with beneficial outcomes for both organizations and newcomers.

Our research also contributes to existing work on positive organizational scholarship, a field of scientific inquiry emphasizing the benefits of personal authenticity to both employees 
and organizations (Cameron et al., 2003). While past research has framed authenticity striving as a personality trait (e.g., Cable and Kay, 2012; Wood et al., 2008), our perspective is that regardless of employees' traits, organizational policies can strategically encourage authenticity at work with benefits to both parties. A related contribution of our paper is its integration of authenticity research into the socialization domain. Although there some evidence in work settings suggests individuals are more productive when their self-views are reflected back to them (Cable and Kay, 2012; Polzer et al., 2002; Swann et al., 2004), these ideas have not been examined in the context of the pivotal period of meeting new work colleagues. Clearly, authentic self-expression helps predict important outcomes in the organizational entry context, and it provides an important conceptual balance to the socialization literature, where uncertainty reduction through values congruence has been the dominant theoretical perspective for the last 30 years.

One important implication of integrating authenticity into socialization processes is that it may help address the homogeneity problem that organizations face when they hire and then socialize people toward similar values (Schneider, 1987) to the point that the organization becomes culturally ingrown and occupies an increasingly narrow ecological niche (Aldrich, 1979). Environmental demands on firms change over time, but organizational cultures are sticky, perpetuated long after the rationale for a cultural value has passed (e.g., Nicholson, 1984; Schneider, 1987). Accordingly, organizational-focused socialization tactics that attempt to press organizational values directly onto impressionable newcomers - while neglecting the fact that values need to solve environmental problems - may sacrifice adaptability.

Integrating the authenticity perspective into the socialization literature may help to address this homogeneity issue, as it encourages newcomers to not only align their behaviors with their best selves but also to use their unique values, perspectives, and strengths to solve organizational problems. As such, a personal-identity socialization process may offer a practical means of helping organizations adapt and maintain a competitive advantage. By making authenticity a core value that is communicated to newcomers, organizations may not only inspire greater workforce contributions but may also enable positive deviance that keeps them fresh and agile. For example, firms such as Southwest Air and Zappos.com hire new employees based in part on their willingness to be themselves at work and solve problems using their unique perspectives and strengths (Freiberg and Freiberg, 1998; Hsieh, 2010), a strategy that has had a 
positive impact on both employee engagement and organizational success.

\section{Strengths, Limitations, and Future Research}

There are a number of strengths of our investigation. First, while considerable research suggests that both employees and organizations are better off when employees are able to be authentic, less is known about how organizations can facilitate authentic self-expression in the workplace (Dutton, Roberts, and Bednar, 2010). We suggested that authenticity initiatives should be pivotal at the very beginning of an employment relationship, as identity negotiation is a critical concern at this stage, and early expectations cast long shadows. Thus, we highlight organizational socialization as a particularly rich environment in which to encourage employees to bring their authentic best selves to work and consequently engage with their work in a more personally fulfilling and productive manner.

Second, we tested our hypotheses by conducting a field experiment, which is one of the strongest methods for maximizing both internal validity and external generalizability (Shadish, Cook, and Campbell, 2002). To enable causal inferences, we compared a control group with two approaches to socialization that reflected different sets of theoretical assumptions. To circumvent problems with self-report data, we examined newcomers' actual departures from the firm and the quality of their actual work (as reported by customers) six months after the experimental manipulations. Thus, the design we employed in our first study minimized typical common method variance problems such as priming, hypothesis guessing, and mood effects. We then constructively replicated our results in a controlled laboratory setting in a different country with different work tasks, where we could further increase internal validity and also examine whether authentic self-expression mediated our results, as hypothesized.

Naturally, our studies also have a number of limitations that point to potential opportunities for future research. First, although we studied both employee departures and customer satisfaction six months after newcomers arrived, it would have been useful to have measured and modeled the outcomes of organizational socialization over an even longer period of time and across multiple customers. Second, although the outcome variables we focused on are clearly organizationally relevant, it also would have been useful to have examined other important outcomes that are both theoretically meaningful and practically relevant, such as newcomers' role innovation (e.g., Ashforth and Saks, 1996; Jones, 1986; Van Maanen and Schein, 1979). Although it is likely that some element of employee innovation is inherent in the 
measure of customer reactions we employed in Study 1, future research could directly model the effect of personal identity socialization on proactivity in meetings, new ideas submitted for products and processes, and willingness to take risks at work.

There are a number of interesting potential boundary conditions surrounding our theory that will be important to test in future research. Although our focus on socialization in an Indian organization helps address calls for socialization research outside the United States (Bauer et al., 1998; Kim et al., 2005), there may be characteristics of Indian culture, the particular organization studied, or even the particular job studied that contributed to the results that we reported. The fact that our second study replicated the main results of Study 1 in a very different context gives us some confidence that the relationships we identified are robust.

Nonetheless, it will be useful for future research to examine our hypotheses in other contexts. For example, it is interesting to consider the appropriateness of authentic socialization in jobs where high-reliability processes and outcomes are necessary (e.g., surgical teams, aircraft carriers). In settings where reliability across individuals results in life or death, it becomes even more important for individuals to apply the best of themselves within the constraints of a reliable, understood process. This may suggest that the framing of a task as an opportunity to use signature strengths, rather than sculpting employees to do the job, becomes more important in some contexts. More broadly, future research could examine whether newcomers trained with an identity manipulation actually do use their signature strengths more in their jobs, or whether the early discussion prompted by our manipulation helped them cognitively frame the work in a way that is consistent with their personal and work goals. Future investigations of these and related questions would further our understanding of how socialization processes emphasizing newcomers' identities or the organization's identity affect newcomers' experiences at work.

Next, employees had little task interdependence in the jobs we examined, which was useful in helping us rule out alternative explanations for the results. However, it is possible that this context offers a conservative test of personal-identity socialization because teams seem to function best - in terms of better relationships, the desire to contribute, the drawing out of each person's unique contributions, and ultimately group performance-when each person feels known and understood by the group (e.g., Swann, Kwan, Polzer, and Milton, 2003; Swann et al., 2004). In fact, some evidence has pointed to relational coordination in teams as a primary causal mechanism connecting high-performance work systems and performance outcomes (e.g., Gittell, 
Seidner, and Wimbush, 2010; Huckman and Staats, 2011). Since personal-identity socialization should increase the quality of employees' relationships, the benefits should theoretically increase for teams that work interdependently (although, of course, future research is needed to test this logic). In particular, it would be useful for future research to focus on employees who work interdependently to measure the extent to which others honor (or do not honor) what newcomers introduce as unique about their identities or strengths.

Across our studies, we focused on the effects of different socialization practices on job attitudes, employee productivity, and retention. Other organizationally important variables may be affected by the framing of socialization processes. Expressing authenticity at work involves voicing one's unique perspective and ideas rather than suppressing ideas in order to conform to group norms. Thus, if newcomers are socialized from the start to reveal and use their unique perspectives, they should demonstrate greater creativity and help improve decision making (Argyris and Schön, 1978; Avery and Steingard, 2008; Morrison and Milliken, 2000; Van Dyne, Ang and Botero, 2003). Future research could examine whether socialization processes focused on individual rather than organizational identity also produce benefits in employees' creative performance.

It also would be interesting for future research to consider whether socialization aimed at highlighting organizational identity could be combined with tactics that leverage newcomers' authentic best selves. For example, if the introduction to socialization focused on organizational strengths and identity, then transitioned into a session on newcomers' best selves as a means of remaining competitive, it may be possible to combine the best of both types of socialization. On the other hand, it is possible that emphasizing the organizational identity creates a strong "normal induction" prime that minimizes the effect of the active individualization approach. It also is worth noting that, conceptually, the greater a newcomer's perceived fit with an organization (Cable and Judge, 1996), the more likely personal identity socialization and organizational identity socialization will yield similar outcomes. This means that hiring people who share the organization's core values might allow the two socialization approaches to be integrated into a seamless whole.

Finally, in this initial investigation, we did not examine whether individual differences moderate the effectiveness of authentic socialization, such that a newcomer's need for uniqueness (Snyder and Fromkin, 1977) or self-concept orientation (Cooper and Thatcher, 2010) 
are boundary conditions of successful authentic socialization. Conceptually, differences between organizations also should serve as moderators of socialization based on individual identity. For example, newcomer authenticity may be more possible when the organization's culture is weak and crystallization is low (Chatman, 1989), perhaps due to organizational age, size, or how loosely coupled it is (Orton and Weick, 1990). Logically, we also would expect that an authenticity-based approach to socialization should be more effective when there is high psychological safety, as self-expression appears to be riskier than conformity (Edmondson, 1999). It also will be interesting to examine whether the effects of the individualization approach to socialization will be stronger or weaker for high-status, highly paid employees than for lowstatus, poorly paid employees. On one hand, it is more likely that emphasizing unique strengths would be a more striking and unique focus for lower-status employees, who may be unaccustomed to having their leaders be interested in their authentic best selves. On the other hand, higher-status individuals likely have greater latitude to sculpt their work environments around their best selves and thereby may be inspired to create environments that allow them to best their best selves more often (Wrzesniewski and Dutton, 2001).

\section{Conclusion}

More than just a theoretically meaningful phenomenon, socialization is serious business for organizational leaders. The process of recruiting, hiring, and training new employees is expensive and time consuming, and quitting is a likely outcome of unsuccessful socialization (Bauer et al., 1998; Fisher, 1986). Failed socialization puts leaders right back where they started after months of investment: trying to recruit new employees. Conversely, successful socialization results in productive, committed employees who are excited to come to work and proud of their role in helping their organization succeed. We found surprisingly large and valuable changes in employees' quality and retention when organizations made relatively small investments in socialization practices that focus on newcomers' personal identities.

Both existing research and anecdotal evidence suggest it is rare for organizations to take an authenticity perspective to socialization, despite the fact that it appears to be valuable for newcomers and causes them to want to commit longer to the organization and inject greater quality into their work. Our research indicates that when organizations find a way to balance this tension - or, even better, use the tension to differentiate themselves to employees as a great place to invest their energies - they appear to have a line on sustained competitive advantage. 


\author{
APPENDIX \\ Instructions used in Study 2, by condition
}

\title{
Control condition
}

The research team you are going to be part of today is called [name of the research team], a creative name that brings together the last names of the two founders of this team: Professor [name] and Professor [name]. Both Professors work at [school name], and conduct research on individual and group decision making.

Now that you have been introduced to the research team, you can start working on today's tasks.

\section{Individual condition}

First, a brief introduction... The research team you are going to be part of today is called [name of the research team], a creative name that brings together the last names of the two founders of this team: Professor [name] and Professor [name]. Both Professors work at [school name], and conduct research on individual and group decision making. [Next screen]

Second, we want to tell you about how working in the research lab would give you the opportunity to express yourself.

The researchers working in the lab, whether they are doctoral students, professors or research assistants, have a common goal: develop scientific insights and, whenever possible, evaluate their impact on decision making in organizations and the broader society.

Whenever possible, the research team members employ experimental approaches with control and treatment groups to cleanly test the effectiveness and efficiency of a given intervention. We conduct our research both in the field (to study decisions in context and test the generalizability of our effects on real decisions) and in the laboratory (to examine the psychological drivers leading to decision mistakes).

By being part of the research team, every member has the chance to brainstorm ideas, propose research projects they want to work on, and think about ways in which these ideas can be tested in the lab or in the field. Graduate students use their projects to strengthen their skills as researchers, in preparation for a job as professors. Undergraduate students help professors and graduate students with their projects or work on their own. Often, these students end up applying for graduate school in the field that is of most interest to them.

No matter what your role is, being part of the team will allow you to discover what it means to work on a research project, and to contribute in all the steps involved in research.

\section{Organizational condition}

First, a brief introduction... The research team you are going to be part of today is called [name of the research team], a creative name that brings together the last names of the two founders of this team: 
Professor [name] and Professor [name]. Both Professors work at [school name], and conduct research on individual and group decision making. [Next screen]

Second, we want to tell you about the research lab's objectives and values, and why it is an outstanding group.

\section{OBJECTIVES AND VALUES}

The researchers working in the lab, whether they are doctoral students, professors or research assistants, have a common goal: develop scientific insights and, whenever possible, evaluate their impact on decision making in organizations and the broader society.

The research team members are interested in research that creates value by improving decisions. The members not only want to help individuals make more effective decisions, but are focused on domains where decisions create value in the broader society. This can be done directly by improving individual decisions, but can also be done through organizational and societal level interventions that affect the decisions of employees, managers, citizens and consumers.

The research team's goals are to develop further insights into how our minds work and examine what interventions lead to improved decision making and behavioral change. The members are particularly interested in identifying value-enhancing interventions that help people overcome mistakes, follow through on their virtuous intention, and avoid decision traps, thus, making everyone better off.

Whenever possible, the research team members employ experimental approaches with control and treatment groups to cleanly test the effectiveness and efficiency of a given intervention. We conduct our research both in the field (to study decisions in context and test the generalizability of our effects on real decisions) and in the laboratory (to examine the psychological drivers leading to decision mistakes).

\section{THE RESEARCH TEAM}

Several people are currently part of the research team, and work on different research projects. They include the two professors leading the lab, graduate students, and undergraduates. Graduate students use their projects to strengthen their skills as researchers, in preparation for a job as professors.

Undergraduate students help professors and graduate students with their projects or work on their own. Often, these students end up applying for graduate school in the field that is of most interest to them.

Both graduate and undergraduate students often comment on the fact that being part of the lab provides them the opportunity to learn and improve on their research. They find the other members to be dedicated to their research and very helpful in contributing to the lab discussions. Some of the lab members' work is regularly published in top academic journals, and is also well received at conferences.

No matter what your role is, being part of the team will allow you to be part of a well functioning and productive group. 


\section{REFERENCES}

Aldrich, H. E.

1979 “Organizations and environments.” Englewood Cliffs, NJ: Prentice-Hall.

Argyris, C., and D. Schön

1978 Organizational learning: A theory of action perspective. Reading, Mass: Addison Wesley.

Ashford, S. J., and J. S. Black

1996 "Proactivity during organizational entry: The role of desire for control." Journal of Applied Psychology, 81: 199-214.

Ashforth, B. E., and A. M. Saks

1996 "Socialization tactics: Longitudinal effects on newcomer adjustment." Academy of Management Journal, 39: 149-178.

Avery, D. R., and D. S. Steingard

2008 "Achieving political trans-correctness: Integrating sensitivity and authenticity in diversity management education.” Journal of Management Education, 32: 269-293.

Avolio, B., and W. Gardner

2005 "Authentic leadership development: Getting to the root of positive forms of leadership." The Leadership Quarterly, 16: 315-338.

Bauer, T. N., and S. G. Green

1998. "Testing the combined effects of newcomer information seeking and manager behavior on socialization." Journal of Applied Psychology, 83: 72-83.

Bauer, T. N., E. W. Morrison, and R. R. Callister

1998 Organizational socialization: A review and directions for future research. In G. R. Ferris (Ed.), Research in Personnel and Human Resource Management (Vol. 16: pp. 149-214). Greenwich, CT: JAI Press.

Baumeister, R. F.

1998 The self. In D. T. Gilbert, S. T. Fiske, and G. Lindzey (Eds.), Handbook of social psychology (4th ed., pp. 680-740).

Bell, E. L.

1990 "The bicultural life experience of career-oriented black women.” Journal of Organizational Behavior, 11: 459-477.

Bell, N. E., and B. M. Staw

1989 People as sculptures versus sculpture: The roles of personality and personal control in organizations. In M. B. Arthur, D. T. Hall, and B. S. Lawrence (Eds.), Handbook of career theory (pp. 232-251). Cambridge, UK: Cambridge University Press.

Budhwar, P., A. Verma, N. Malhotra, and A. Mukherjee

2009 "Insights into the Indian Call Centre Industry: Can internal marketing help tackle high employee turnover?" Journal of Services Marketing, 23(5): 351-362.

Cable, D. M., and V. Kay

2012 "Striving for self verification during organizational entry." Academy of Management Journal, 55(2).

Cable, D., and T. A. Judge

1997 “Interviewers' perceptions of person-organization fit and organizational selection decisions." Journal of Applied Psychology, 82, 546-561.

Cable, D. M., and C. Parsons

2001 "Socialization tactics and person-organization fit." Personnel Psychology, 54: 1-22. 
Cable, D., \& Judge, T. A.

1996. "Person-organization fit, job choice decisions, and organizational entry." Organizational Behavior and Human Decision Processes, 67: 294-311.

Cameron, K. S., J. E. Dutton, R. E. Quinn, and A. Wrzensniewski

2003 Developing a discipline of positive organizational scholarship. In K. S. Cameron, J. E. Dutton, and R. E. Quinn (Eds.), Positive organizational scholarship (pp. 361-370). San Francisco: Berrett-Koehler.

Chatman, J. A.

1989 "Improving interactional organizational research: A model of person-organization fit." Academy of Management Review, 14: 333-349.

1991. "Matching people and organizations: Selection and socialization in public accounting firms." Administrative Science Quarterly, 36: 459-484.

Cleves, M., W. W. Gould, and R. Guiterrez

2004 An introduction to survival analysis using Stata. Revised Edition. Stata Press.

Cooper, D., and S. M. Thatcher

2010 "Identification in organizations: The role of self-concept orientations and identification motives." Academy of Management Review, 35: 516-538.

Cropanzano, R., D. E. Rupp, and Z. S. Byrne

2003 "The relationship of emotional exhaustion to work attitudes, job performance, and organizational citizenship behaviors.” Journal of Applied Psychology, 88: 160-169.

Dutton, J. E., J. M. Roberts, and J. Bednar

2010 "Pathways for positive identity construction at work: Four types of positive identity and the building of social resources." Academy of Management Review, 35: 265-293.

Edmondson, A. C.

1999 "Psychological safety and learning behavior in work teams." Administrative Science Quarterly, 44, 350-383.

Feldman, D. C., and J. M. Brett

1983 "Coping with new jobs: A comparative study of new hires and job changers." Academy of Management Journal, 26: 258-272.

Fisher, C. D.

1986 Organizational socialization: An integrative review. In K. M. Rowland and G. R. Ferris (Eds.), Research in personnel and human resources management (Vol. 4, pp. 101-145). Greenwich, CT: JAI Press.

Freiberg, K., and J. Freiberg

1998 Nuts! Southwest Airlines' Crazy Recipe for Business and Personal Success. Broadway: New York.

Garman, A. N., P. W. Corrigan, and S. B. Morris

2002 "Staff burnout and patient satisfaction: Evidence of relationships at the care unit level." Journal of Occupational Health Psychology, 7: 235-241.

Gittell, J. H., R. Seidner, and J. Wimbush.

2010. Relational model of how high-performance work systems work. Organization Science, 21: 490-506.

Goffman, E.

1959 The presentation of self in everyday life. New York: Doubleday Anchor.

Goldberg, L., and A. Grandey

2007 "Display rules versus display autonomy: Emotion regulation, emotional exhaustion, and 
task performance in a call center simulation.” Journal of Occupational Health Psychology, 12: 301-318.

Grandey, A. A.

2003 "When 'the show must go on': Surface acting and deep acting as determinants of emotional exhaustion and peer-rated service delivery." Academy of Management Journal, 46: 86-96.

Griffin, A., A. Colella, and S. Goparaju

2000 "Newcomer and organizational socialization tactics: An interactionist perspective." Human Resources Management Review, 10: 453-474.

Guignon, $\mathbf{C}$.

2004 On being authentic. Routledge: NY.

Harter, S.

2002 Authenticity. In C. R. Snyder and S. Lopez (Eds.), Handbook of positive psychology (pp. 382-394). New York: Oxford University Press.

Heatherton, T. F., and J. Polivy

1991 "Development and validation of a scale for measuring state self-esteem." Journal of Personality and Social Psychology, 60: 895-910.

Hewlin, P. F.

2003 "And the award for best actor goes to...: Facades of conformity in organizational settings." Academy of Management Review, 28: 633-656.

Higgins, E. T.

1989 Self-discrepancy theory: What patterns of self-beliefs cause people to suffer? In L. Berkowitz (Ed.), Advances in experimental social psychology, Vol. 22 (pp. 93-136). San Diego, CA: Academic Press.

Hochschild, A. R.

1979 "Emotion work, feeling rules and social structure." American Journal of Sociology, 85: 551-575.

Hochschild, A. R.

1983 The managed heart: Commercialization of human feeling. Berkeley, CA: University of California Press.

Hsieh, T.

2010 Delivering Happiness: A Path to Profits, Passion, and Purpose. Business Plus, New York. Huckman, R. S. and B. R. Staats.

2011 "Fluid tasks and fluid teams: The impact of diversity in experience and team familiarity on team performance." Manufacturing \& Service Operations Management 13: 310-328.

Ibarra, $\mathbf{H}$.

2003 Working identity: Unconventional strategies for reinventing your career. Cambridge, MA: Harvard Business School Press.

Illies, R., F. Morgeson, and J. Nahrgang

2005 "Authentic leadership and eudaemonic well-being: Understanding leader-follower outcomes.” The Leadership Quarterly, 16: 373-394.

Kahn, W. A.

1990 "Psychological conditions of personal engagement and disengagement at work." Academy of Management Journal, 33: 692-724.

Kahn, W. A.

1992 "To be fully there: Psychological presence at work." Human Relations, 45: 321-349. 
Kernis, M. H.

2003 "Toward a conceptualization of optimal self-esteem." Psychological Inquiry, 14: 1-26.

Kim, T. Y., D. Cable, and S. P. Kim

2005 "Socialization tactics, employee proactivity, and person-organization fit." Journal of Applied Psychology, 90: 232-241.

Jones, G. R.

1986 "Socialization tactics, self-efficacy, and newcomers' adjustments to organizations." Academy of Management Journal, 29: 262-279.

Lopez, F., and K. Rice

2006 "Preliminary development and validation of a measure of relationship authenticity." Journal of Counseling Psychology, 53: 362-371.

Louis, M. R.

1980 "Surprise and sense making: What newcomers experience in entering unfamiliar organizational settings.” Administrative Science Quarterly, 25: 226-251.

Lueke, S. B., and Svyantek, D. J.

2000 "Organizational socialization in the host country: The missing link in reducing expatriate turnover.” International Journal of Organizational Analysis, 8, 380-440.

Marantz, A.

2011 My Summer at an Indian Call Center. Mother Jones, July 5. http://m.motherjones.com/politics/2011/05/indian-call-center-americanization

Martin, J., K. Knopoff, and C. Beckman

1998 "An alternative to bureaucratic impersonality and emotional labor: Bounded emotionality at The Body Shop." Administrative Science Quarterly, 43: 429-469.

Maslach, C., W. B. Schaufeli, and M. P. Leiter

2001 "Job burnout." Annual Review of Psychology, 52: 397-422.

Melamed, S., A. Shirom, S. Toker, S. Berliner, and I. Shapira

2006 "Burnout and risk of cardiovascular disease: Evidence, possible causal paths, and promising research directions." Psychological Bulletin, 132: 327-353.

Miller, V. D., and F. M. Jablin

1991 "Information seeking during organizational entry: Influences, tactics, and a model of the process." Academy of Management Review, 16: 92-120.

Morrison, E. W., and F. J. Milliken

2000 "Organizational silence: A barrier to change and development in a pluralistic world." Academy of Management Review, 25: 706-731.

Morrison, E. W.

1993 "Longitudinal study of the effects of information seeking on newcomer socialization." Journal of Applied Psychology, 78: 173-183.

Mueller, J. S., Melwani, S., \& Goncalo, J. A.

2012. "The bias against creativity: Why people desire but reject creative ideas." Psychological Science, 21: 13-17.

Nicholson, $\mathbf{N}$.

1984 "A theory of work role transitions." Administrative Science Quarterly, 29(2): 172191.

O'Reilly, C., and J. Chatman

1996 "Culture as social control: Corporations, cults, and commitment." Research in Organizational Behavior, 18: 167-210.

O'Reilly, C. \& Chatman, J. 
1986. Organizational commitment and psychological attachment: The effects of compliance, identification, and internalization on prosocial behavior. Journal of Applied Psychology, 71: 492-499.

Orton J. D., and K. E. Weick

1990 "Loosely coupled systems: a reconceptualization." Academy of Management Review, 15: 203-223.

Polzer, J. T., L. P. Milton, and W. B. Swann

2002 "Capitalizing on diversity: Interpersonal congruence in small work groups." Administrative Science Quarterly, 47: 296-324.

Pratt, M. G.

2000 "The good, the bad, and the ambivalent: Managing identification among Amway distributors." Administrative Science Quarterly, 45: 456-493.

Preacher, K. J., and A. F. Hayes

2004 "SPSS and SAS procedures for estimating indirect effects in simple mediation models." Behavior Research Methods, Instruments, and Computers, 36: 717-731.

Quinn, R. P., and L. G. Shepard

1974 The 1972 - 1973 quality of employment survey. Ann Arbor: Institute for Social Research, University of Michigan.

Reichers, A. E.

1987. An interactionist perspective on newcomer socialization rates. Academy of Management Review, 12: 278-287.

Roberts, L. M., J. E. Dutton, G. M. Spreitzer, E. D. Heaphy, and R. E. Quinn

2005 "Composing the reflected best-self portrait: Building pathways for becoming extraordinary in work organizations.” Academy of Management Review, 30, 712-736.

Roberts, L. M.

2012 Reflected Best Self Engagement at Work: Positive Identity, Alignment, and the Pursuit of Vitality and Value Creation. Oxford University Press Handbook of Happiness (Chief editors Ilona Boniwell and Susan David, Section editors Kim Cameron and Arran Caza).

Rogers, C.

1951 Client-centered therapy: Its current practice, implications and theory. London: Constable.

Ryan, R. M.

1993 Agency and organization: Intrinsic motivation, autonomy and the self in psychological development (Vol. 40). Lincoln: University of Nebraska Press.

Ryan, R. M., and E. L. Deci

2001 "On happiness and human potential: A review of research on hedonic and eudaimonic well-being." Annual Review of Psychology, 52: 141-166.

Ryan, R. M., J. G. La Guardia, and L. J. Rawsthorne

2005 "Self-complexity and the authenticity of self-aspects: Effects on well being and resilience to stressful events.” North American Journal of Psychology, 3: 431-447.

Ryff, C., and C. Keyes

1995 "The structure of psychological well-being revisited." Journal of Personality and Social Psychology, 60: 719-727.

Schaufeli, W. B., A. B. Bakker, and M. Salanova

2006 "The measurement of work engagement with a short questionnaire: A cross-national study." Educational and Psychological Measurement, 66: 701-716.

Schein, E. H. 
1971 "The individual, the organization, and the career: a conceptual scheme." Journal of Applied Behavioral Science, 7(4): 401-426.

Schneider, B.

1987 “The people make the place." Personnel Psychology, 40: 437-453.

Seligman, M. E.P.

2002 Authentic Happiness: Using the New Positive Psychology to Realize Your Potential for Lasting Fulfillment.

Seligman, M. E .P., T. A. Steen, N. Park, and C. Peterson

2005 "Positive psychology progress: empirical validation of interventions." American Psychologist, 60: 410-421.

Selk, J.

2008 10-Minute Toughness: The Mental Training Program for Winning Before the Game Begins. McGraw-Hill.

Settles, I. H., R. M. Sellers, and A. Damas Jr.

2002 "One role or two? The function of psychological separation in role conflict." Journal of Applied Psychology, 87: 574-582.

Shamir, B., R. J. House, and M. B. Arthur

1993 "The motivational effects of charismatic leadership: A self-concept based theory." Organization Science, 4(4): 577-594.

Shadish, W. R., T. D. Cook, and D. T. Campbell

2002 Experimental and Quasi-Experimental Designs for Generalized Causal Inference. Boston: Houghton-Mifflin.

Sheldon, K. M., and B. A. Bettencourt

2002 "Psychological need-satisfaction and subjective well-being within social groups." British Journal of Social Psychology, 41: 25-38

Sheldon, K., and E. Deci

1996 The self-determination scale. University of Rochester. See Self Determination Theory. An Approach to Human Motivation and Personality. The Self-Determination Scale.

Sherif, M. (Retrieved May 20, 2012). http://www.psych.rochester.edu/SDT/measures/selfdet.html.

1958 "Superordinate goals in the reduction of intergroup conflict." American Journal of Sociology, 4: 349-356.

Snyder, C. R., and H. L. Fromkin

1977 "Abnormality as a positive characteristic: The development and validation of a scale measuring need for uniqueness.” Journal of Abnormal Psychology, 86: 518-527.

Swann, W. B., Jr.

1990 To be adored or to be known: The interplay of self-enhancement and self-verification. In R. M. Higgins and E. T. Sorrentino (Eds.), Handbook of motivation and cognition, vol. 2: 408-448. New York: Guilford.

Swann, W. B., J. T. Polzer, D. C. Seyle, and S. J. Ko

2004 "Finding value in diversity: Verification of personal and social self-views in diverse groups." Academy of Management Review, 29: 9-27.

Swann, W. B., Jr., L. P. Milton, and J. T. Polzer

2000 "Should we create a niche or fall in line? Identity negotiation and small group effectiveness." Journal of Personality and Social Psychology, 79: 238-250.

Swann, W. B., Kwan, V. S. Y., Polzer, J. T., \& Milton, M. P. 
2003. "Fostering group identification and creativity in diverse groups: The role of individuation and self-verification." Personality and Social Psychology Bulletin, 29: 1396-1406

Taris, T. W.

2006 "Is there a relationship between burnout and objective job performance? A critical review of 16 studies." Work and Stress, 20: 316-334.

Thoits, P. A.

1991 "On merging identity theories and stress research." Social Psychology Quarterly, 54: 101-112.

Van Dyne, L., S. Ang, and I. C. Botero

2003 "Conceptualizing employee silence and employee voice as multidimensional constructs." Journal of Management Studies, 40: 1359-1392.

Van Maanen, J., and E. H. Schein

1979 Toward a theory of organizational socialization. In B. M. Staw (Ed.), Research in Organizational Behavior (vol. 1, pp. 209-264). Greenwich, CT: JAI Press.

Waterman, A. S.

1993 "Two conceptions of happiness: Contrasts of personal expressiveness (eudaimonia) and hedonic enjoyment." Journal of Personality and Social Psychology, 64: 678-691.

2005 "When effort is enjoyed: Two studies of intrinsic motivation for personally salient activities." Motivation and Emotion, 29: 165-188.

Wiesenfeld, B. M., W. B. Swann, J. Brockner, and C. Bartel

2007 "Is more fairness always preferred? Self-esteem moderates reactions to procedural justice." Academy of Management Journal, 50: 1235-1253.

Wood, A. M., P. A. Linley, J. Maltby, M. Baliousis, and S. Joseph

2008 "The authentic personality: A theoretical and empirical conceptualization and the development of the Authenticity Scale.” Journal of Counseling Psychology, 55: 385-399.

Wright, T. A., and R. Cropanzano

1998 "Emotional exhaustion as a predictor of job performance and voluntary turnover." Journal of Applied Psychology, 83: 486-493.

Wrzesniewski, A., and J. E. Dutton

2001 "Crafting a job: Revisioning employees as active crafters of their work." Academy of Management Review, 26: 179-201.

Zapf, D.

2002 "Emotion work and psychological well-being: A review of the literature and some conceptual considerations." Human Resource Management Review, 12: 237-268. 


\section{TABLES}

TABLE 1A.

Agent summary by account, Study 1 .

\begin{tabular}{lccccc} 
& \multicolumn{7}{c}{ Customer Account } \\
\hline Condition & $\mathbf{1}$ & $\mathbf{2}$ & $\mathbf{3}$ & $\mathbf{4}$ & Total \\
\hline Individual & 15 & 38 & 43 & 0 & 96 \\
Organizational & 0 & 37 & 21 & 43 & 101 \\
Control & 110 & 250 & 48 & 0 & 408 \\
Total & 125 & 325 & 112 & 43 & \\
\hline
\end{tabular}

TABLE $1 B$.

Agent summary by location, Study 1 .

\begin{tabular}{lcccc} 
& \multicolumn{3}{c}{ Location } \\
\hline Condition & $\mathbf{1}$ & $\mathbf{2}$ & $\mathbf{3}$ & Total \\
\hline Individual & 58 & 38 & 0 & 96 \\
Organizational & 23 & 35 & 43 & 101 \\
Control & 250 & 158 & 0 & 408 \\
Total & 331 & 231 & 43 & \\
\hline
\end{tabular}


TABLE 2.

Variables used Study 1.

\begin{tabular}{|c|c|}
\hline Variable & Description \\
\hline Turnover & $\begin{array}{l}\text { An indicator variable set to one if an agent departed Wipro on or prior to May } 30 \text {, } \\
2011 \text {, and set to } 0 \text {, otherwise. }\end{array}$ \\
\hline $\begin{array}{l}\text { Customer } \\
\text { satisfaction }\end{array}$ & $\begin{array}{l}\text { The average of an agent's customer satisfaction scores, as rated by randomly sampled } \\
\text { customers that she has served. }\end{array}$ \\
\hline Duration & The total number of days that an agent has worked at Wipro. \\
\hline Organizational & $\begin{array}{l}\text { An indicator set to one if an agent received the organizational identity manipulation, } \\
\text { and zero otherwise. }\end{array}$ \\
\hline Individual & $\begin{array}{l}\text { An indicator set to one if an agent received the individual identity manipulation, and } \\
\text { zero otherwise. }\end{array}$ \\
\hline Control & $\begin{array}{l}\text { An indicator set to one if an agent received no identity manipulation, and zero } \\
\text { otherwise. }\end{array}$ \\
\hline Age & The age of the agent when she started working at Wipro. \\
\hline $\begin{array}{l}\text { Prior } \\
\text { experience }\end{array}$ & The number of months of experience the agent had prior to starting at Wipro. \\
\hline Male & An indicator variable set to one if an agent is male, and zero if the agent is female. \\
\hline
\end{tabular}

TABLE 3.

Summary statistics, Study 1.

\begin{tabular}{|c|c|c|c|c|c|c|c|c|c|c|}
\hline Variable & Mean & $\sigma$ & 1 & 2 & 3 & 4 & 5 & 6 & 7 & 8 \\
\hline 1. Turnover & 0.55 & 0.50 & & & & & & & & \\
\hline 2. Customer satisfaction & 0.61 & 0.20 & -0.19 & & & & & & & \\
\hline 3. Duration & 131.1 & 67.0 & -0.78 & 0.10 & & & & & & \\
\hline 4. Organizational & 0.17 & 0.37 & -0.04 & -0.03 & 0.16 & & & & & \\
\hline 5. Individual & 0.16 & 0.37 & -0.13 & -0.03 & 0.11 & -0.19 & & & & \\
\hline 6. Control & 0.67 & 0.47 & 0.13 & 0.06 & -0.22 & -0.64 & -0.63 & & & \\
\hline 7. Age & 24.30 & 3.89 & 0.01 & 0.01 & -0.06 & -0.09 & 0.04 & 0.04 & & \\
\hline 8. Prior experience (months) & 4.54 & 15.36 & -0.15 & -0.03 & 0.14 & 0.02 & 0.27 & -0.23 & 0.37 & \\
\hline 9. Male & 0.82 & 0.39 & 0.01 & 0.19 & 0.02 & 0.02 & -0.03 & 0.01 & 0.04 & 0.08 \\
\hline
\end{tabular}

Note. Bold denotes significance of less than $5 \% . \mathrm{N}=605$ except for duration and customer satisfaction where $\mathrm{N}=600$ and $\mathrm{N}=97$, respectively. 
TABLE 4.

Regression results, Study 1.

\begin{tabular}{|c|c|c|c|c|c|c|c|c|}
\hline & \multicolumn{3}{|c|}{ Conditional Logistic Regresssion on Turnover } & \multicolumn{3}{|c|}{ Hazard Model on Turnover } & \multicolumn{2}{|c|}{ Customer Satisfaction Regression } \\
\hline & (1) & (2) & (3) & (4) & $(5)$ & (6) & (7) & $(8)$ \\
\hline \multirow{2}{*}{ Organizational } & & $1.252 * *$ & $1.379^{*}$ & & $0.648 * *$ & $0.717 * *$ & & -0.0559 \\
\hline & & $(0.473)$ & $(0.609)$ & & $(0.229)$ & $(0.272)$ & & $(0.0491)$ \\
\hline \multirow{2}{*}{ Control } & & $0.944 * * *$ & $1.152 * * *$ & & $0.769 * * *$ & $0.872 * * *$ & & $-0.105^{*}$ \\
\hline & & $(0.238)$ & $(0.111)$ & & $(0.149)$ & $(0.155)$ & & $(0.0437)$ \\
\hline \multirow{2}{*}{ Age } & $0.0439 * * *$ & $0.0422 * * *$ & $0.0320 * * *$ & $0.0333 * *$ & $0.0277^{*}$ & 0.0169 & -0.00202 & -0.00272 \\
\hline & $(0.0115)$ & $(0.0108)$ & $(0.00552)$ & $(0.0107)$ & $(0.0111)$ & $(0.0138)$ & $(0.00628)$ & $(0.00669)$ \\
\hline \multirow{2}{*}{ Prior experience } & $-0.0290 * * *$ & $-0.0230 * * *$ & $-0.0253 * *$ & $-0.0245 * * *$ & $-0.0198 * * *$ & $-0.0215^{* *}$ & -0.000732 & -0.000652 \\
\hline & $(0.00542)$ & $(0.00606)$ & $(0.00917)$ & $(0.00470)$ & $(0.00531)$ & $(0.00825)$ & $(0.000914)$ & $(0.000918)$ \\
\hline \multirow{2}{*}{ Male } & 0.137 & 0.109 & 0.210 & 0.0672 & 0.0438 & 0.107 & -0.0179 & 0.0277 \\
\hline & $(0.174)$ & $(0.174)$ & $(0.315)$ & $(0.130)$ & $(0.127)$ & $(0.214)$ & $(0.0413)$ & $(0.0396)$ \\
\hline Location 2 & $\begin{array}{l}-0.774 \\
(0.760)\end{array}$ & $\begin{array}{l}-1.329 \\
(1.098)\end{array}$ & $\begin{array}{l}-1.276 \\
(1.516)\end{array}$ & $\begin{array}{l}-0.824 \\
(0.443)\end{array}$ & $\begin{array}{l}-1.247 \\
(0.791)\end{array}$ & $\begin{array}{l}-1.248 \\
(1.188)\end{array}$ & $\begin{array}{c}0.0577 \\
(0.0352)\end{array}$ & $\begin{array}{c}0.0491 \\
(0.0537)\end{array}$ \\
\hline Account 2 & $\begin{array}{c}\text { Model } \\
\text { conditions }\end{array}$ & $\begin{array}{l}\text { Model } \\
\text { conditions }\end{array}$ & $\begin{array}{c}\text { Model } \\
\text { conditions }\end{array}$ & $\begin{array}{l}-0.758 \\
(0.430)\end{array}$ & $\begin{array}{l}-1.141 \\
(0.785)\end{array}$ & $\begin{array}{l}- \\
-\end{array}$ & Model & Model \\
\hline Account 3 & $\begin{array}{c}\text { on account } \\
\text { so no }\end{array}$ & $\begin{array}{c}\text { on account } \\
\text { so no }\end{array}$ & $\begin{array}{c}\text { on account } \\
\text { so no }\end{array}$ & $\begin{array}{c}0.0991 \\
(0.0789)\end{array}$ & $\begin{array}{c}0.222 \\
(0.136)\end{array}$ & $\begin{array}{c}1.404 \\
(1.014)\end{array}$ & $\begin{array}{c}\text { examines } \\
\text { performance }\end{array}$ & $\begin{array}{l}\text { examines } \\
\text { performance }\end{array}$ \\
\hline Account 4 & $\begin{array}{c}\text { estimates for } \\
\text { parameters }\end{array}$ & $\begin{array}{l}\text { estimates for } \\
\text { parameters }\end{array}$ & $\begin{array}{l}\text { estimates for } \\
\text { parameters }\end{array}$ & $\begin{array}{l}-1.187^{*} \\
(0.475)\end{array}$ & $\begin{array}{l}-1.585 \\
(0.943)\end{array}$ & $\begin{array}{l}- \\
-\end{array}$ & $\begin{array}{l}\text { within only } \\
\text { Account } 2\end{array}$ & $\begin{array}{l}\text { within only } \\
\text { Account } 2\end{array}$ \\
\hline Constant & - & - & - & - & - & - & $0.673 * * *$ & $0.715^{* *}$ \\
\hline constant & - & - & - & - & - & - & $(0.150)$ & $(0.161)$ \\
\hline Individuals & 605 & 605 & 437 & 600 & 600 & 432 & 97 & 97 \\
\hline McFadden's Pseudo $\mathrm{R}^{2}$ & 0.0288 & 0.0466 & 0.0639 & - & - & - & - & - \\
\hline Log Pseudolikelihood & -391.5 & -384.4 & -274.4 & -1976 & -1976 & -1335 & - & - \\
\hline $\mathrm{R}^{2}$ & - & - & - & - & - & - & 0.0223 & 0.0662 \\
\hline Wald chi-squared & - & - & - & $326.9 * * *$ & $152.3 * * *$ & 1.10 & - & - \\
\hline F Statistic & - & - & - & - & - & - & 2.376 & $2.925^{*}$ \\
\hline
\end{tabular}


TABLE 5.

Summary statistics, Study 2.

\begin{tabular}{|c|c|c|c|c|c|c|c|c|c|c|c|}
\hline Condition & Mean & $\begin{array}{l}\text { Standard } \\
\text { deviation }\end{array}$ & 1 & 2 & 3 & 4 & 5 & 6 & 7 & 8 & 9 \\
\hline 1. Personal distinctiveness & 3.35 & 1.49 & 1 & & & & & & & & \\
\hline 2. Socialization intensity & 3.12 & 1.22 & -.035 & 1 & & & & & & & \\
\hline 3. Self-expression & 4.67 & 1.34 & $.38^{* *}$ & -.08 & 1 & & & & & & \\
\hline 4. Self-esteem & 4.75 & 1.33 & $.24^{* *}$ & $-.27^{* * *}$ & $.33^{* * *}$ & 1 & & & & & \\
\hline 5. Self-verification & 4.09 & 1.24 & $.26^{* * *}$ & .09 & $.58^{* * *}$ & $.33^{* * *}$ & 1 & & & & \\
\hline $\begin{array}{l}\text { 6. Liking of research team } \\
\text { members }\end{array}$ & 3.92 & 0.94 & $.43^{* * *}$ & .09 & $.48^{* * *}$ & $.34^{* * *}$ & $.44^{* * *}$ & 1 & & & \\
\hline 7. Work engagement & 3.89 & 1.45 & $.49^{* * *}$ & -.12 & $.54^{* * *}$ & $.32^{* * *}$ & $.27^{* * *}$ & $.46^{* * *}$ & 1 & & \\
\hline 8. Job satisfaction & 4.11 & 1.35 & $.485^{* * *}$ & -.06 & $.54^{* * *}$ & $.30^{* * *}$ & $.29^{* * *}$ & $.50^{* * *}$ & $.57^{* * *}$ & 1 & \\
\hline 9. Job performance & 109.05 & 7.62 & $.27^{* * *}$ & -.07 & $.34^{* * *}$ & .01 & .11 & $.17^{*}$ & $.34^{* * *}$ & $.30^{* * *}$ & 1 \\
\hline 10. Retention & $61.1 \%$ & 0.49 & $.17^{*}$ & -.08 & $.41^{* * *}$ & $.14^{+}$ & $.18^{*}$ & $.20^{* *}$ & $.26^{* *}$ & $.25^{* *}$ & $.18^{*}$ \\
\hline
\end{tabular}

Notes. ${ }^{*} p<.05,{ }^{* *} p<.01,{ }^{* * *} p<.001,{ }^{+} p<.10$ 
TABLE 6.

Summary statistics by condition, Study 2.

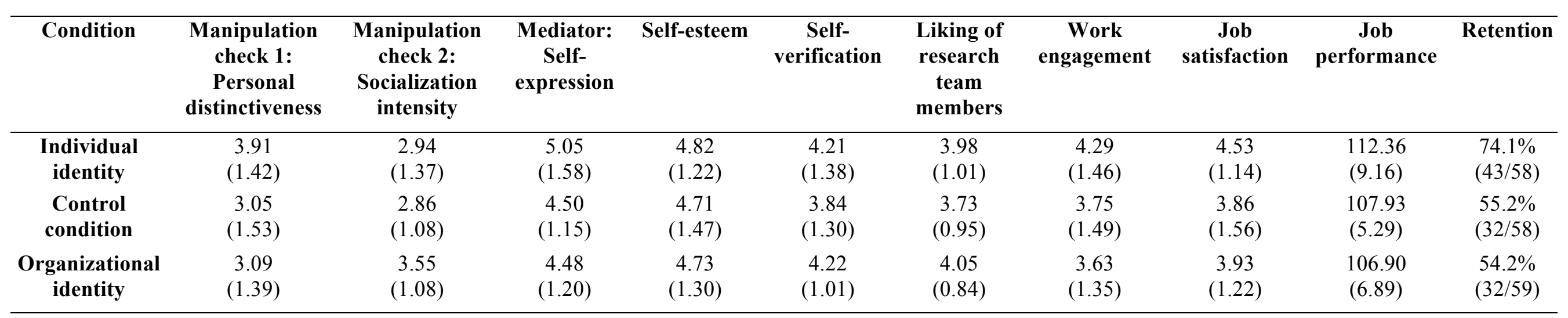

Note. Standard deviations are reported in parentheses. 